\title{
Thermodynamic Theory of Freezing and Melting of Water and Aqueous Solutions
}

\author{
Vitaly I. Khvorostyanov \\ Central Aerological Observatory, Dolgoprudny, Moscow, Russian Federation
}

\author{
Judith A. Curry* \\ School of Earth and Atmospheric Sciences, Georgia Institute of Technology, Atlanta, Georgia 30332
}

Received: May 3, 2004; In Final Form: September 14, 2004

\begin{abstract}
This paper examines the freezing and melting of water and aqueous solutions in the framework of classical nucleation theory. On the basis of thermodynamical principles, general equations for the critical germ radius and free energy are derived that express these properties as functions of temperature, solution molality, pressure, and finite size of freezing/melting particles. This theory is applied to the study of liquid-solid phase transitions: homogeneous, heterogeneous, and quasi-heterogeneous freezing of aqueous solutions and surface melting of ice. Simple analytical expressions for the corresponding freezing and melting critical temperatures are derived and solved numerically using an iteration procedure, whereby the melting and freezing temperatures are calculated for solutions with various chemical compositions, concentrations, and pressures. Comparison of the theory with experimental data shows good agreement and indicates that this approach allows reproduction of measured melting and freezing temperatures as functions of solution molality (or water saturation ratio) and pressure over wide ranges for many geophysical applications.
\end{abstract}

\section{Introduction}

Freezing and melting of water and aqueous solutions plays an important role in many geophysical processes. The glaciation of clouds ${ }^{1-6}$ influences their radiative properties, precipitation, planetary albedo, and climate. ${ }^{6-10}$ Seawater freezing and melting control global sea ice cover, and formation of ice in leads and polynyas in polar seas dominates the heat and moisture exchange between the polar atmosphere and ocean..$^{9-11}$ Ice crystals in the polar stratosphere play a key role in the chemical reactions that lead to formation of ozone holes. ${ }^{12-14}$ The processes of premelting (melting below bulk triple point) are involved in environmental phenomena such as frost heave, ${ }^{15,16}$ sliding of glaciers, ${ }^{9,17}$ and electrification of clouds and lightning. ${ }^{6,18,19}$

Cirrus clouds in the upper troposphere cover $20-30 \%$ of the globe ${ }^{20}$ and substantially influence the global radiative budget and atmospheric chemistry. ${ }^{5-10,21,22}$ It is commonly accepted that cirrus clouds form by direct freezing (homogeneous or heterogeneous) of aqueous solution drops (haze particles). ${ }^{21-44}$ However, the mechanisms of freezing, and their parametrization in cloud and climate models, remain very uncertain. ${ }^{21,22,39}$ This uncertainty has stimulated numerous laboratory, field, and theoretical studies of freezing at low temperatures of various aqueous solutions, directed to understanding cirrus formation. Laboratory experiments on homogeneous freezing temperatures and nucleation rates for solutions have provided an understanding of the general features of homogeneous freezing at low temperatures. However, there are still significant discrepancies among the various experimental results. ${ }^{5,21,22,29,38-54}$

Two different approaches have been used in theoretical studies and recent models of cirrus formation. Several models directly use classical nucleation theory for calculation of crystal

* Author to whom correspondence should be addressed. Phone: (404) 894-3948;.Fax: (404) 894-5638. E-mail: curryja@eas.gatech.edu. nucleation rates, ${ }^{28,29,34,35,37,39,40,72}$ including further development and refinements of the theory itself. ${ }^{1-5,21,22,28-36,39,41-44}$ More frequently, models use various parametrizations of nucleation rates or freezing temperatures that are explicitly or implicitly related to classical nucleation theory. ${ }^{23-27,32,33,38,39,44}$

Because laboratory data on freezing temperatures are still uncertain and direct calculation of the nucleation rates is faced with uncertainties in the input parameters, one of the most frequently used methods of determining freezing temperatures is an empirical linear relation between depressions of the homogeneous freezing temperatures, ${ }^{55,56} \Delta T_{\mathrm{f}, \text { hom }}$, and bulk melting temperatures, $\Delta T_{\mathrm{m}}$, as $\Delta T_{\mathrm{f}, \mathrm{hom}}=\lambda \Delta T_{\mathrm{m}}$. This approach $^{23-25,27,32,39}$ with $\lambda=1.7$ and experimental data on $\Delta T_{\mathrm{m}}$ yields reasonable nucleation rates and crystal concentrations and is currently used in many models. However, recent laboratory observations $^{21,22,39}$ indicate that $\lambda$ is not a universal constant; values of $\lambda$ are different for various substances and depend on temperature and molality of solution drops, varying over the range $1.5-3$, and may exceed ${ }^{52 c} 5$.

The question arises as to whether it is possible to derive both $\Delta T_{\mathrm{f}, \mathrm{hom}}$ and $\Delta T_{\mathrm{m}}$ and the $\Delta T_{\mathrm{f}, \mathrm{hom}}-\Delta T_{\mathrm{m}}$ relation from theory and to relate $\lambda$ to basic physical quantities. Although Rasmus$\operatorname{sen}^{55}$ supposed that this relation cannot be explained by classical nucleation theory, the sufficiently close agreement of nucleation rates calculated with classical nucleation theory and with the $\lambda$ relation ${ }^{22,39}$ suggests that this empirical relation could be derived from classical nucleation theory. Moreover, if such a derivation was possible, then a link could be established between homogeneous freezing processes at low temperatures $T_{\mathrm{f} \text {,hom }}<-35$ ${ }^{\circ} \mathrm{C}$ (e.g., cirrus and polar stratospheric clouds) and freezingmelting processes at higher temperatures $\left(\sim 0\right.$ to $\left.-30^{\circ} \mathrm{C}\right)$ that govern such geophysical processes as formation of sea ice and motion of glaciers.

Another interesting link occurs between the solution and the pressure effects of the freezing and melting processes. Labora- 
tory experiments have shown $\mathrm{n}^{57,58,52 \mathrm{a}}$ that the isomolal dependencies of $T_{\mathrm{f}, \mathrm{hom}}(p), T_{\mathrm{m}}(p)$ at varying pressure are equivalent to the isobaric dependencies $T_{\mathrm{f}, \mathrm{hom}}(\bar{M}), T_{\mathrm{m}}(\bar{M})$ with varying molality $\bar{M}$. An interpretation of this fact was given ${ }^{57,58}$ in terms of equivalent perturbation of a hydrogen bonding network by pressure and solution, and more recently, ${ }^{52 \mathrm{a}}$ in terms of "effective" solution concentration and water activity $a_{\mathrm{w}}$ (or saturation ratio $S_{\mathrm{w}}$ ). However, it is not clear why this equivalence occurs and if it can be directly derived from nucleation theory along with a simple relation between pressure and molality.

Toward addressing these issues, this paper examines freezing and melting processes using classical nucleation theory and extending the treatment of critical radii and energies of nucleation. In section 2, we briefly outline the basic thermodynamic equations and derive general expressions for the critical liquid/solid germ radius and energy as functions of temperature, water saturation ratio (or molality), pressure, and finite size of freezing/melting particles, extending the previous equations of classical nucleation theory. ${ }^{1-5,68,69}$ These expressions are employed in section 3 for derivation of the equations for homogeneous, heterogeneous, and quasi-heterogeneous freezing temperatures and melting temperature. Results of calculations for atmospheric pressure and comparison with experiments are given in section 4 , and applications to the pressure-induced freezing and melting at high pressure are considered in section 5 .

\section{Critical Radius and Free Energy of a Germ at Freezing and Surface Melting}

To derive the critical radius and free energy of a germ for freezing or melting, we consider a spherical germ of the bulk phase (2) forming in the volume or at the surface of another bulk phase (1). The entropy equation is written as ${ }^{2,3,5}$

$$
\mathrm{d}\left[\frac{\mu_{1}\left(p, T, a_{1}\right)}{T}\right]+\frac{h_{10}}{T^{2}} \mathrm{~d} T-\frac{v_{10}}{T} \mathrm{~d} p-R \mathrm{~d} \ln a_{1}=0
$$

where $T$ is temperature, $p$ is pressure, $R$ is the universal gas constant, $h$ is the molar enthalpy, $\mu$ is the molar chemical potential, $a$ is the activity, and $v$ is the specific volume. The subscript 1 refers to phase 1 , and the subscript 0 refers to the pure substance. An analogous equation can be written for phase 2.

If phase 2 is solid (e.g., ice) that nucleates heterogeneously on the surface of a foreign substrate, then an additional term should be added to $\mu_{2}$, which arises from the elastic strain $\epsilon$ caused by the misfit between ice and substrate lattices. ${ }^{1,4,5,70}$ This term was not accounted for in previous derivations of equations for critical radius and free energy, ${ }^{2,3,5}$ but it is frequently added ${ }^{1,5}$ to the final equations. The term associated with the elastic strain is formulated ${ }^{70}$ as $M_{2} C_{\epsilon} \epsilon^{2} / \rho_{2}$, with $M_{2}$ and $\rho_{2}$ being the molecular weight and the density of phase 2 and $C_{\epsilon}=1.7 \times 10^{11} \mathrm{dyn}^{-2}$. Substituting (2.1) for $\mu_{1}$ and the corresponding expression for $\mu_{2}$ into the condition of equilibrium $\mathrm{d}\left(\mu_{1} / T\right)=\mathrm{d}\left(\mu_{2} / T\right)$, we obtain the general equation for phase equilibrium

$$
\begin{array}{r}
-\frac{\left(h_{10}-h_{20}\right)}{T} \mathrm{~d} T+v_{10} \mathrm{~d} p_{1}-v_{20} \mathrm{~d} p_{2}-M_{2} T \mathrm{~d}\left(\frac{C_{\epsilon} \epsilon^{2}}{\rho_{2}}\right)+ \\
R T \mathrm{~d} \ln \left(\frac{a_{1}}{a_{2}}\right)=0
\end{array}
$$

This equation provides a general description of phase equilibrium that can be applied to a variety of phase transitions. ${ }^{2,3,5}$

We consider here three particular cases under variable external pressure and solution concentration: (1) volume homogeneous and heterogeneous freezing of aqueous solution drops; (2) surface freezing of solutions; and (3) surface melting of ice crystals.

2.1. Volume Freezing. For volume freezing, consider a solution drop with radius $r_{\mathrm{d}}$ in humid air. An ice germ with radius $r_{\mathrm{cr}}$ forms inside the drop either directly (homogeneous volume freezing) or on the surface of a foreign substrate (heterogeneous volume freezing); then phase 1 is the liquid solution and phase 2 is ice. Such a configuration was previously considered, ${ }^{1-5}$ and the expressions for the critical radii were derived under constant external pressure. ${ }^{1-5,21,28,30,34-37,42,68}$ Here, we consider variable pressure along with variable temperature and saturation ratio. In the context of eq 2.2, all quantities denoted by " 0 " refer to pure water. Nucleation of a new phase occurs if the size of the initial germ of the new phase reaches a critical value. To derive a general dependence of the ice germ critical radius $r_{\text {cr }}$ on temperature $T$, saturation ratio $S_{\mathrm{w}}$, and pressure $p$, we start from eq 2.2. If an ice germ is approximated by a sphere as in case of homogeneous freezing ${ }^{2,3,5}$ or as a spherical cap at the surface of insoluble substrate as for heterogeneous freezing, , 1,5,5,36 then the internal pressures inside a crystal, $p_{\mathrm{i}}$, and inside a liquid solution drop, $p_{\mathrm{s}}$, can be expressed in terms of external pressure $p$ with use of conditions of mechanical equilibrium

$$
\mathrm{d} p_{\mathrm{i}}=\mathrm{d} p_{\mathrm{s}}+\mathrm{d}\left(\frac{2 \sigma_{\mathrm{is}}}{r_{\mathrm{cr}}}\right), \quad \mathrm{d} p_{\mathrm{s}}=\mathrm{d} p+\mathrm{d}\left(\frac{2 \sigma_{\mathrm{sa}}}{r_{\mathrm{d}}}\right)
$$

where subscripts i and s refer to ice, and solution, respectively; $\sigma_{\text {is }}$ and $\sigma_{\mathrm{sa}}$ are the surface tensions at the ice-solution and solution-air interfaces. Equation 2.3 describes the equilibrium between an ice germ and liquid solution drop and equilibrium between the liquid drop and environmental air.

Substituting eq 2.3 into eq 2.2 , and dividing by $M_{\mathrm{w}}$, we obtain

$$
\begin{array}{r}
-\frac{L_{\mathrm{m}}}{T} \mathrm{~d} T-\frac{A_{\rho}}{\rho_{\mathrm{i}}} \mathrm{d}\left(p+\frac{2 \sigma_{\mathrm{sa}}}{r_{\mathrm{d}}}\right)-\frac{1}{\rho_{\mathrm{i}}} \mathrm{d}\left(\frac{2 \sigma_{\mathrm{is}}}{r_{\mathrm{cr}}}\right)-\mathrm{d}\left(\frac{C_{\epsilon} \epsilon^{2}}{\rho_{\mathrm{i}}}\right)+ \\
\frac{R T}{M_{\mathrm{w}}} \mathrm{d} \ln a_{\mathrm{w}}=0
\end{array}
$$

where $L_{\mathrm{m}}=\left(h_{\mathrm{w} 0}-h_{\mathrm{i} 0}\right) / M_{\mathrm{w}}$ is the specific latent heat of melting, and the densities of water and ice are given by $\rho_{\mathrm{w}}=M_{\mathrm{w}} / v_{\mathrm{w}}$ and $\rho_{\mathrm{i}}=M_{\mathrm{w}} / v_{\mathrm{i}} \cdot A_{\rho}=1-\rho_{\mathrm{i}} / \rho_{\mathrm{w}}$ is the density function, $a_{\mathrm{w}}$ is the water activity, and we have assumed that the ice activity $a_{\mathrm{i}}$ $=1$ due to the small retention coefficient. ${ }^{5,15}$ Equation 2.4 differs from analogous equations $s^{2,3,5}$ by the presence of additional terms with $p$ and $\epsilon$. We can integrate eq 2.4 from $T$ to the triple point temperature $T_{0}$, and from $p$ to $p_{0}$ with the usual boundary conditions ${ }^{2,3,5}\left(a_{\mathrm{w}}=1, r_{\mathrm{cr}}=r_{\mathrm{d}}=\infty, p=p_{0}\right.$, and $\epsilon=0$ at $T=$ $\left.T_{0}\right)$, to obtain

$$
L_{\mathrm{m}}^{\mathrm{ef}} \ln \frac{T_{0}}{T}=\frac{2 \sigma_{\mathrm{is}}}{\rho_{\mathrm{i}} r_{\mathrm{cr}}}+\frac{2 \sigma_{\mathrm{sa}}}{\rho_{\mathrm{i}} r_{\mathrm{d}}}+\frac{A_{\rho}}{\rho_{\mathrm{i}}} \Delta p+\frac{C_{\epsilon} \epsilon^{2}}{\rho_{\mathrm{i}}}-\frac{R T}{M_{\mathrm{w}}}\left(\frac{A_{\mathrm{K}}}{r_{\mathrm{d}}}+\ln a_{\mathrm{w}}\right)
$$

where $L_{\mathrm{m}}^{\mathrm{ef}}=\int_{T}^{T_{0}}\left[L_{\mathrm{m}}(T) / T\right] \mathrm{d} T / \ln \left(T_{0} / T\right)$ is the effective average melting heat, $\Delta p=p-p_{0}$, and $A_{\mathrm{K}}=2 M_{\mathrm{w}} \sigma_{\mathrm{sa}} / \rho_{\mathrm{w}} R T$ is the Köhler's parameter. The water activity $a_{\mathrm{w}}$ is often assumed ${ }^{30,52 \mathrm{a}}$ to be equal to the water saturation ratio $S_{\mathrm{w}}$ or is calculated ${ }^{27}$ from the Köhler equation $A_{\mathrm{K}} / r_{\mathrm{d}}+\ln a_{\mathrm{w}}=\ln S_{\mathrm{w}}$. We also use 
this equation and substitute it into the last term in eq 2.5. Note that each term on the right-hand side of eq 2.5 is positive, so that $\ln \left(T_{0} / T\right) \geq 0$ and $T \leq T_{0}$ (i.e., eq 2.5 describes lowering of the bulk triple point by all of the above factors). Solving for $r_{\mathrm{cr}}$ from eq 2.5 , we obtain

$$
r_{\mathrm{cr}}=\frac{2 \sigma_{\mathrm{is}}}{\rho_{\mathrm{i}} L_{\mathrm{m}}^{\text {ef }} \ln \left[\left(T_{0} / T\right) S_{\mathrm{w}}^{G} \exp \left(-H_{\mathrm{v}, \mathrm{fr}}\right)\right]}
$$

$H_{\mathrm{v}, \mathrm{fr}}=$

$$
\left(\Delta \rho \Delta p / \rho_{\mathrm{w}}+2 \sigma_{\mathrm{sa}} / r_{\mathrm{d}}+C_{\epsilon} \epsilon^{2}\right) /\left(\rho_{\mathrm{i}} L_{\mathrm{m}}^{\mathrm{ef}}\right), \quad G=R T /\left(M_{\mathrm{w}} L_{\mathrm{m}}^{\mathrm{ef}}\right)
$$

where $G$ is a dimensionless parameter, and $\Delta \rho=\rho_{\mathrm{w}}-\rho_{\mathrm{i}}$. This equation accounts for the effects of temperature, water saturation ratio, pressure, elastic misfit strain, and finite size of a freezing drop on $r_{\mathrm{cr}}$ and is valid for both heterogeneous $(\epsilon \neq 0)$ and homogeneous $(\epsilon=0)$ freezing.

Equation 2.6 can be compared with previously derived expressions by considering particular cases. For the simplest case with constant pressure $(\Delta p=0)$, no misfit strain $(\epsilon=0)$, and a bulk solution $\left(1 / r_{\mathrm{d}}=0\right)$, we have $H_{\mathrm{fr}}=0$. If additionally $S_{\mathrm{w}}=1$ (pure water and no external sources of supersaturation), then eq 2.6 is simplified to be the classical equation ${ }^{68}$

$$
r_{\mathrm{cr}}=\frac{2 \sigma_{\mathrm{iw}}}{\rho_{\mathrm{i}} L_{\mathrm{m}}^{\mathrm{ef}} \ln \left(T_{0} / T\right)}
$$

where $\sigma_{\text {iw }}$ is the surface tension at the ice-water interface. This equation is often used to describe the triple point lowering in polycrystalline crystals and melting point shifts due to varying crystal size (Gibbs-Thomson effect). 2,3,15,64,71 If misfit strain is included, then eq 2.6 becomes

$$
r_{\mathrm{cr}}=\frac{2 \sigma_{\mathrm{iw}}}{\rho_{\mathrm{i}} L_{\mathrm{m}}^{\mathrm{ef}} \ln \left(T_{0} / T\right)-C_{\epsilon} \epsilon^{2}}
$$

This generalization of Thomson's equation for $r_{\mathrm{cr}}$ has been determined previously ${ }^{1,4,6}$ for heterogeneous nucleation. In the presence of a solvent or external source of supersaturation, $S_{\mathrm{w}}$ $\neq 1$, but still for $\epsilon=0$ and $\Delta p=0$, we have from eq 2.6 another expression previously derived ${ }^{34,35}$

$$
r_{\mathrm{cr}}=\frac{2 \sigma_{\mathrm{is}}}{\rho_{\mathrm{i}} L_{\mathrm{m}}^{\mathrm{ef}} \ln \left[\left(T_{0} / T\right) S_{\mathrm{w}}^{G}\right]}
$$

Similar equations for the case of homogeneous nucleation were obtained previously, 2,21,28,30,42 but $r_{\mathrm{cr}}$ was expressed in a slightly different form using water activity $a_{\mathrm{w}}$ or molar fraction $X_{\mathrm{s}}$. The use of $S_{\mathrm{w}}$ instead of $a_{\mathrm{w}}$ or $X_{\mathrm{s}}$ can be more convenient in some applications such as cloud models where $S_{\mathrm{w}}$ is a readily determined environmental variable. (Although $a_{\mathrm{w}}$ and $S_{\mathrm{w}}$ are close in many cases at $S_{\mathrm{w}}<1$, they may differ and even have different signs at $S_{\mathrm{w}} \approx 1$ due to the curvature effects, thus leading to different $r_{\mathrm{cr}}$.) For applications in cloud models, note that in a rising or sinking air parcel, the environmental $S_{\mathrm{w}}$ can somewhat differ from the equilibrium value near the drop used in the derivation above; however, a solution drop at $S_{\mathrm{w}}<1$ grows or shrinks rapidly until the equilibrium size and $S_{\mathrm{w}}$ are reached..$^{5,34,36}$ The characteristic time of adjustment to equilibrium varies from $10^{-4} \mathrm{~s}$ for $r_{\mathrm{d}}=10^{-2} \mu \mathrm{m}$ to a few seconds for $r_{\mathrm{d}}$ of a few micrometers, and equilibrium exists in most cases with moderate vertical velocities, $, 34,36,39$ even with rapid turbulent fluctuations. ${ }^{5}$ In cases with updrafts of a few meters per second and a very cold environment, deviations of haze particles from equilibrium may last longer and corrections to environmental $S_{\mathrm{w}}$ may be required; ${ }^{39,36}$ nonetheless, even under these conditions, many cloud models assume equilibrium $S_{\mathrm{w}}$ with reasonable accuracy. ${ }^{39}$ The cloud drops grow at slight supersaturation $\delta_{\mathrm{w}}>0$, and when considering their freezing via immersion or contact modes, $S_{\mathrm{w}}$ near the drop surface can be obtained by subtracting $\delta_{\mathrm{w}}$ from the environmental $S_{\mathrm{w}}$; this correction is rather small because $\delta_{\mathrm{w}}$ generally does not exceed $0.5-1 \%$ and is commonly $<0.1 \%$.

In the presence of a solvent or external source of supersaturation, $S_{\mathrm{w}} \neq 1$, but still for $\Delta p=0$, we have from eq 2.6 the following equation

$$
r_{\mathrm{cr}}=\frac{2 \sigma_{\mathrm{is}}}{\rho_{\mathrm{i}} L_{\mathrm{m}}^{\mathrm{ef}} \ln \left[\left(T_{0} / T\right) S_{\mathrm{w}}^{G}\right]-C_{\epsilon} \epsilon^{2}}
$$

This equation was obtained for heterogeneous nucleation ${ }^{36}$ and has been used to simulate ice crystal formation in atmospheric clouds. ${ }^{36 \mathrm{~b}, 40,72}$ Note that in the case $\epsilon=0$ and $T \rightarrow T_{0}$ or for concentrated solutions, eq 2.6 converts into

$$
r_{\mathrm{cr}}=\frac{2 M_{\mathrm{w}} \sigma_{\mathrm{is}}}{R T \rho_{\mathrm{i}} \ln S_{\mathrm{w}}}
$$

and resembles Kelvin's ${ }^{69}$ expression for nucleation of a crystal from the vapor except that it contains $\sigma_{\text {is }}$ instead of $\sigma_{\text {iv }}$ for nucleation from the vapor. Because $\sigma_{\text {is }} \approx 1 / 4 \sigma_{\text {iv }}$, eq $2.6 \mathrm{e}$ shows that ice nucleation by water freezing is energetically much more favorable than direct nucleation from the vapor. The pressure dependence in eq 2.6 has not been previously accounted for. So, eq 2.6 generalizes and unifies all of these particular cases for the critical germ radius and is used below to establish equivalence between pressure, solution, and temperature effects on freezing and melting.

Applicability of eq 2.6 can be illustrated as follows. Because the denominator of eq 2.6 should be positive, we have an inequality

$$
\rho_{\mathrm{i}} L_{\mathrm{m}}^{\mathrm{ef}} \ln \left(\frac{T_{0}}{T} S_{\mathrm{w}}^{G}\right)-\frac{\Delta \rho}{\rho_{\mathrm{w}}} \Delta p-C_{\epsilon} \epsilon^{2}-\frac{2 \sigma_{\mathrm{sa}}}{r_{\mathrm{d}}} \geq 0
$$

Solving eq 2.8 for $r_{\mathrm{d}}$ provides a condition for the minimum size of the freezing drops

$$
r_{\mathrm{d}} \geq \frac{2 \sigma_{\mathrm{sa}}}{\rho_{\mathrm{i}} L_{\mathrm{m}}^{\mathrm{ef}} \ln \left(\frac{T_{0}}{T} S_{\mathrm{w}}^{G}\right)-\frac{\Delta \rho}{\rho_{\mathrm{w}}} \Delta p-C_{\epsilon} \epsilon^{2}}
$$

An estimation for standard pressure $(\Delta p=0), \epsilon=0$, and pure water $\left(S_{\mathrm{w}}=1\right)$ gives $r_{\mathrm{d}} \geq 1.3 \times 10^{-6} \mathrm{~cm}$ at $T=263.15 \mathrm{~K}$ $\left(-10^{\circ} \mathrm{C}\right)$ and $r_{\mathrm{d}} \geq 3.2 \times 10^{-7} \mathrm{~cm}$ at $T=233.15 \mathrm{~K}\left(-40{ }^{\circ} \mathrm{C}\right)$. However, freezing experiments ${ }^{5,45,46}$ show that the drops never freeze homogeneously at $-10{ }^{\circ} \mathrm{C}$ and freeze at $-40^{\circ} \mathrm{C}$ with larger radii $\approx 0.2-0.5 \mu \mathrm{m}$. Thus, this condition is necessary but not sufficient, because it corresponds to zero nucleation rates. A generalization to finite nucleation rates is given in section 3 based on eq 2.6.

Solving (2.8) for $T$ provides a condition for the freezing temperature $T_{\mathrm{f} \text {,hom }}$

$$
T_{\text {f,hom }} \leq T_{0} S_{\mathrm{w}}^{G} \exp \left[-\frac{1}{\rho_{\mathrm{i}} L_{\mathrm{m}}^{\mathrm{ef}}}\left(\frac{\Delta \rho}{\rho_{\mathrm{w}}} \Delta p+C_{\epsilon} \epsilon^{2}+\frac{2 \sigma_{\mathrm{sa}}}{r_{\mathrm{d}}}\right)\right]
$$


which yields an upper boundary for $T_{\mathrm{f} \text {,hom }}$ as a function of molality, pressure, and the radius of a freezing drop. This expression will be generalized further in section 3 to account for finite nucleation rates.

2.2. Surface Freezing. There are several possible geometrical configurations of an ice germ forming at the surface of a solution drop. We consider the case when an ice germ is located at the interface between the humid air and solution drop. A similar configuration was discussed ${ }^{1-6,36}$ for the case of the liquid/solid interface when an ice germ forms heterogeneously at the surface of a foreign substance. Here, we deal with the situation when solid forms at the interface of its own melt and gas (vapor or humid air). A similar configuration was recently described conceptually and called "pseudoheterogeneous freezing", ${ }^{6,67}$ and the criterion for surface freezing, $\sigma_{\mathrm{ia}}-\sigma_{\mathrm{sa}}<\sigma_{\mathrm{is}}$, was derived for this process. Here, we consider this process in more detail and derive its critical radius and energy. Assume that an ice germ represents a spherical segment (lens or "tiny pancake ice") bounded by two surfaces. ${ }^{3}$ An outer surface (in contact with air) is a spherical segment with radius $r_{\mathrm{cr}}$ and the inner surface (in contact with the solution drop) is planar. This case represents a mixture of homogeneous and heterogeneous processes because (a) it proceeds homogeneously without a foreign substance and (b) due to incomplete wettability (i.e., small but nonzero contact angles between ice and water ${ }^{6,60-63,73}$ ) the geometrical decrease of free energy is similar to those in heterogeneous freezing as described in section 3 .

Because both the ice germ and the solution drop are in mechanical equilibrium with the environmental air, it follows that the pressures inside the solution drop, $p_{\mathrm{s}}$, and ice crystal cap, $p_{\mathrm{i}}$, with corresponding radii $r_{\mathrm{d}}$ and $r_{\mathrm{cr}}$ are described by the Laplace equation

$$
\mathrm{d} p_{\mathrm{s}}=\mathrm{d} p+\mathrm{d}\left(\frac{2 \sigma_{\mathrm{sa}}}{r_{\mathrm{d}}}\right), \quad \mathrm{d} p_{i}=\mathrm{d} p+\mathrm{d}\left(\frac{2 \sigma_{\mathrm{ia}}}{r_{\mathrm{cr}}}\right)
$$

where $\sigma_{\mathrm{ia}}$ is the surface tension at the ice-air interface. Substituting eq 2.11 into eq 2.2 without the strain term $(\epsilon=0)$ because we do not consider undissolved particulates here, we obtain

$$
\begin{aligned}
&-\frac{L_{\mathrm{m}}}{T} \mathrm{~d} T+\left(\frac{1}{\rho_{\mathrm{w}}}-\frac{1}{\rho_{\mathrm{i}}}\right) \mathrm{d} p+\mathrm{d}\left(\frac{2 \sigma_{\mathrm{sa}}}{\rho_{\mathrm{w}} r_{\mathrm{d}}}\right)- \mathrm{d}\left(\frac{2 \sigma_{\mathrm{ia}}}{\rho_{\mathrm{i}} r_{\mathrm{cr}}}\right)+ \\
& \frac{R T}{M_{\mathrm{w}}} \mathrm{d} \ln a_{\mathrm{w}}=0
\end{aligned}
$$

Integration of eq 2.12 with the boundary conditions $\mathrm{s}^{2,3,5} r_{\mathrm{cr}}=r_{\mathrm{d}}$ $=\infty, a_{\mathrm{w}}=1$, and $p=p_{0}$ at $T=T_{0}$, yields

$$
L_{\mathrm{m}}^{\mathrm{ef}} \ln \frac{T_{0}}{T}=\frac{2 \sigma_{\mathrm{ia}}}{\rho_{\mathrm{i}} r_{\mathrm{cr}}}-\frac{2 \sigma_{\mathrm{sa}}}{\rho_{\mathrm{w}} r_{\mathrm{d}}}+\left(\frac{1}{\rho_{\mathrm{i}}}-\frac{1}{\rho_{\mathrm{w}}}\right) \Delta p-\frac{R T}{M_{\mathrm{w}}} \ln a_{\mathrm{w}}
$$

It is interesting to note that Dufour and Defay ${ }^{2}$ considered a different configuration, drop and crystal coexisting in air, and obtained a similar equation except without the pressure term and having a more complicated expression for the solution term. One can see that eq 2.13 contains both positive and negative terms on the right-hand side. In particular, the terms with pressure and $a_{\mathrm{w}}$ are positive, causing the lowering of the freezing temperature with increasing pressure and molality, described in the next sections. These equations predict situations with $T$ $<T_{0}$, which is a physical state, and with $T>T_{0}$, which predicts existence of ice above bulk triple point (superheating of crystals) and is an unobservable state. ${ }^{2}$ This problem is caused by limitations of classical nucleation theory, ${ }^{73}$ with its predictions symmetric relative to $T_{0}$; this symmetry is absent in the density functional theory that avoids freezing point elevation. ${ }^{73}$ Now, replacing again $a_{\mathrm{w}}$ with $S_{\mathrm{w}}$, in eq 2.13 , we obtain finally the critical radius $r_{\mathrm{cr}}$ of an ice germ at the solution-air interface

$$
\begin{gathered}
r_{\mathrm{cr}}=\frac{2 \sigma_{\mathrm{ia}}}{\rho_{\mathrm{i}} L_{\mathrm{m}}^{\mathrm{ef}} \ln \left[\left(T_{0} / T\right) S_{\mathrm{w}}^{G} \exp \left(-H_{\mathrm{s}, \mathrm{fr}}\right)\right]} \\
H_{\mathrm{s}, \mathrm{fr}}=\left(\frac{\Delta \rho \Delta p}{\rho_{\mathrm{i}}}-\frac{2 \sigma_{\mathrm{sa}}}{r_{\mathrm{d}}}\right) /\left(\rho_{\mathrm{w}} L_{\mathrm{m}}^{\mathrm{ef}}\right)
\end{gathered}
$$

Note that eq 2.14 for surface freezing contains the surface tension ice-air $\sigma_{\text {ia }}$ instead of $\sigma_{\text {is }}$ for solution-ice in eq 2.6 for volume freezing, which reflects the difference in freezing mechanisms.

2.3. Surface Melting. The numerous theories of surface melting mentioned in the Introduction include intergranular melting in polycrystalline crystals, melting at grain and vein junctions, and evaluatiuon of the lowering of the bulk triple points and melted film thickness, which account for various mechanisms of premelting, effects of crystal size, and impurities. $3,6,15,16,18,19,59,62-65,71,73$

We consider here one simple mechanism of surface melting: nucleation of a liquid drop at the crystal/gas interface when melting is incomplete (i.e., drops occur instead of a liquid film). ${ }^{3}$ We consider a quasi-heterogeneous process of nucleation of a liquid germ at the surface of its own solid at small but finite contact angles. This type of surface melting with occurrence of small drops at the crystal surface has been observed in laboratory experiments. $6,15,60-62$ This case is similar to surface freezing considered in the previous section except with reversed configuration of the liquid and ice. To determine the droplet critical radius $r_{\mathrm{d}}$ and melting temperature $T_{\mathrm{m}}$, we again begin with eq 2.2. For melting, phase 1 is ice, phase 2 is the liquid, and $-L_{\mathrm{m}}$ $=\left(h_{\mathrm{i} 0}-h_{\mathrm{w} 0}\right) / M_{\mathrm{w}}$. We consider a liquid germ that is located at the interface of the crystal and humid air and represents a spherical segment (lens) bounded by two surfaces. An outer surface (in contact with vapor or humid air) is a spherical segment with radius $r_{\mathrm{d}}$, and the bottom surface (in contact with ice crystal) is approximated by a planar surface.

Using the conditions of mechanical equilibrium, we write for the pressures inside the liquid lens $p_{\mathrm{s}}$ and crystal $p_{\mathrm{i}}$ the Laplace equations

$$
\mathrm{d} p_{\mathrm{s}}=\mathrm{d} p+\mathrm{d}\left(\frac{2 \sigma_{\mathrm{sa}}}{r_{\mathrm{d}}}\right), \quad \mathrm{d} p_{\mathrm{i}}=\mathrm{d} p+\mathrm{d}\left(\frac{2 \sigma_{\mathrm{ia}}}{r_{\mathrm{cr}}}\right)
$$

Substituting eq 2.16 into eq 2.2 , we obtain

$$
\begin{aligned}
\frac{L_{\mathrm{m}}}{T} \mathrm{~d} T+\left(\frac{1}{\rho_{\mathrm{i}}}-\frac{1}{\rho_{\mathrm{w}}}\right) \mathrm{d} p+\mathrm{d}\left(\frac{2 \sigma_{\mathrm{ia}}}{\rho_{\mathrm{i}} r_{\mathrm{cr}}}\right)- \\
\mathrm{d}\left(\frac{2 \sigma_{\mathrm{sa}}}{\rho_{\mathrm{w}} r_{\mathrm{d}}}\right)-\frac{R T}{M_{\mathrm{w}}} \mathrm{d} \ln a_{\mathrm{w}}=0
\end{aligned}
$$

Integration of eq 2.17 with the same boundary conditions $a_{\mathrm{w}}=$ $1, r_{\mathrm{d}}=r_{\mathrm{cr}}=\infty$, and $p=p_{0}$ at $T=T_{0}$ yields

$$
L_{\mathrm{m}}^{\mathrm{ef}} \ln \frac{T_{0}}{T}=-\frac{2 \sigma_{\mathrm{sa}}}{\rho_{\mathrm{w}} r_{\mathrm{d}}}+\frac{2 \sigma_{\mathrm{ia}}}{\rho_{\mathrm{i}} r_{\mathrm{cr}}}+\left(\frac{1}{\rho_{\mathrm{i}}}-\frac{1}{\rho_{\mathrm{w}}}\right) \Delta p-\frac{R T}{M_{\mathrm{w}}} \ln a_{\mathrm{w}}
$$

which formally coincides with eq 2.10 , except that the unknown is here $r_{\mathrm{d}}$. The terms with pressure at $\Delta p>0$ and solution effects 
are positive, shifting the melting temperatures $T_{\mathrm{m}}$ below the bulk triple point. At negative pressure $(\Delta p<0)$ (e.g., in the case of internal melting of ice caused by strong radiative heating and formation of "Tyndall flowers") when ice may exist in metastable equilibrium ${ }^{6}$ at up to $+8{ }^{\circ} \mathrm{C}$ and $\Delta p \approx-10^{3}$ bar, eq 2.18 describes competition of the negative pressure, which causes elevation of $T_{\mathrm{m}}$ (possibly to well above $0{ }^{\circ} \mathrm{C}$ ) and the counteracting solution effects $\left(a_{\mathrm{w}}<1\right)$ that tend to lower $T_{\mathrm{m}}$. Again replacing $a_{\mathrm{w}}$ with $S_{\mathrm{w}}$, we find from eq 2.18 the critical radius $r_{\mathrm{d}}$ of a liquid germ

$$
\begin{gathered}
r_{\mathrm{d}}=\frac{2 \sigma_{\mathrm{sa}}}{-\rho_{\mathrm{w}} L_{\mathrm{m}}^{\mathrm{ef}} \ln \left[\left(T_{0} / T\right) S_{\mathrm{w}}^{G} \exp \left(-H_{\mathrm{m}}\right)\right]} \\
H_{\mathrm{m}}=\frac{\rho_{\mathrm{w}}}{\rho_{\mathrm{i}}}\left(\frac{\Delta \rho \Delta p}{\rho_{\mathrm{w}}}+\frac{2 \sigma_{\mathrm{ia}}}{r_{\mathrm{cr}}}\right) /\left(\rho_{\mathrm{w}} L_{\mathrm{m}}^{\mathrm{ef}}\right)
\end{gathered}
$$

Equation 2.19 differs from eqs 2.6 and 2.14 for freezing by the opposite sign of the temperature term $\ln \left(T_{0} / T\right)$.

\section{Critical Freezing and Melting Temperatures}

To derive the critical temperature of both homogeneous and heterogeneous freezing, we can use equations ${ }^{1-6}$ for the nucleation rates, $J_{\mathrm{h}}$

$$
J_{\mathrm{h}}\left(T, S_{\mathrm{w}}\right)=C_{\mathrm{h}}(T) \exp \left(-\frac{\Delta F_{\mathrm{act}}(T)+\Delta F_{\mathrm{cr}}\left(T, S_{\mathrm{w}}\right)}{k T}\right)
$$

where $\Delta F_{\mathrm{cr}}\left(T, S_{\mathrm{w}}\right)$ is the critical Helmholtz free energy of an ice germ for freezing or of a liquid germ for melting, $\Delta F_{\text {act }}$ is the activation energy, $k$ is the Boltzmann constant, and $C_{\mathrm{h}}$ is a normalizing factor. The quantities $J_{\mathrm{h}}$ and $C_{\mathrm{h}}$ will be denoted later with indices "hom" and "het" for homogeneous and heterogeneous processes, respectively.

In classical nucleation theory, the free energy of germ formation $\Delta F_{\mathrm{cr}}\left(T, S_{\mathrm{w}}\right)$ is written ${ }^{1-6}$ as a sum of the positive surface term, $\sim r^{2}$, and a negative volume term, proportional to $r^{3}$, and to the difference of the free energies of water $F_{\mathrm{w}}$ and ice $F_{\mathrm{i}}$

$$
\Delta F(r)=-\left(F_{\mathrm{w}}-F_{\mathrm{i}}\right)\left({ }^{4} / 3\right) \pi r^{3} \rho_{\mathrm{i}}+4 \pi r^{2} \sigma_{\mathrm{is}}
$$

The critical energy $\Delta F_{\text {cr }}$ is obtained by differentiating $\Delta F(r)$ by $r_{\mathrm{cr}}$, then $\left(F_{\mathrm{w}}-F_{\mathrm{i}}\right)$ is expressed via $r_{\mathrm{cr}}$ and is substituted into eq 3.2 to yield $\Delta F_{\mathrm{cr}}=(4 \pi / 3) \sigma_{\mathrm{is}} r_{\mathrm{cr}}^{2}$ for a spherical crystal or $\Delta F_{\mathrm{cr}}=(4 \pi / 3) \sigma_{\mathrm{is}} r_{\mathrm{cr}}^{2} f\left(m_{\mathrm{is}}, x\right)$ for a crystal with geometry of a spherical cap, and $f\left(m_{\text {is }}, x\right)$ is a geometrical factor. ${ }^{1,5}$ Substituting eq 2.6 for $r_{\text {cr }}$ for solution into the last expression, we obtain the critical free energy for volume freezing as a function of temperature, solution concentration (supersaturation), pressure, and misfit strain

$$
\begin{aligned}
& \Delta F_{\mathrm{cr}}=\frac{4}{3} \pi \sigma_{\mathrm{is}} r_{\mathrm{cr}}^{2} f\left(m_{\mathrm{is}}, x\right)= \\
& \frac{16 \pi}{3} \frac{\sigma_{\mathrm{is}}^{3} f\left(m_{\mathrm{is}}, x\right)}{\left\{\rho_{\mathrm{i}} L_{\mathrm{m}}^{\mathrm{ef}} \ln \left[\frac{T_{0}}{T} S_{\mathrm{w}}^{G} \exp \left(-H_{\mathrm{v}, \mathrm{fr}}\right)\right]\right\}^{2}}
\end{aligned}
$$

Here, $H_{\mathrm{v}, \mathrm{fr}}$ is defined in eq 2.7, and $f\left(m_{\mathrm{is}}, x\right)$ is the geometrical factor derived by Fletcher ${ }^{1}$ for the cap

$$
\begin{gathered}
f(m, x)=(1 / 2)\left\{1+[(1-m x) / y]^{3}+x^{3}\left(2-3 \psi+\psi^{3}\right)+\right. \\
\left.3 m x^{2}(\psi-1)\right\} \\
\psi=(x-m) / y, \quad y=\left(1-2 m x+x^{2}\right)^{1 / 2}
\end{gathered}
$$

where $x=r_{\mathrm{N}} / r_{\mathrm{cr}}$, with $r_{\mathrm{N}}$ being the radius of insoluble particle on which surface a crystal forms for the case of heterogeneous freezing, $x=r_{\mathrm{d}} / r_{\mathrm{cr}}$, and $x=r_{\mathrm{cr}} / r_{\mathrm{d}}$; for the cases of surface freezing and melting, $\theta_{\text {is }}$ is the corresponding contact angle, and $m_{\mathrm{is}}=\cos \theta_{\mathrm{is}}$ is the wettability parameter at the ice-substrate interface for the case of heterogeneous freezing and at the icesolution interface for surface freezing and ice melting. For constant pressure $(\Delta p=0)$ and freezing of bulk solutions or large drops $\left(r_{\mathrm{d}}=\infty\right)$, the factor $H_{\mathrm{v}, \text { fr }}$ becomes $C_{\epsilon} \epsilon^{2} / \rho_{\mathrm{i}} L_{\mathrm{m}}^{\mathrm{ef}}$, and eq 3.3 reduces to the expression derived earlier for heterogeneous freezing ${ }^{36}$

$$
\Delta F_{\mathrm{cr}}=\frac{(16 \pi / 3) \sigma_{\mathrm{is}}^{3} f\left(m_{\mathrm{is}}, x\right)}{\left[\rho_{\mathrm{i}} L_{\mathrm{m}}^{\mathrm{ef}} \ln \left(\frac{T_{0}}{T} S_{\mathrm{w}}^{G}\right)-C_{\epsilon} \epsilon^{2}\right]^{2}}
$$

which for pure water $\left(S_{\mathrm{w}}=1\right)$ converts into the previous expressions $^{1,4-6}$ for $\Delta F_{\mathrm{cr}}$.

3.1. Homogeneous Freezing. For homogeneous freezing, $\theta_{\text {is }}$ $=180^{\circ}, m_{\mathrm{is}}=-1$, and $f\left(m_{\mathrm{is}}, x\right)=1, C_{\epsilon}=0$; equations for $r_{\mathrm{cr}}$ and $\Delta F_{\text {cr }}$ are simplified

$$
r_{\mathrm{cr}}=\frac{2 \sigma_{\mathrm{is}}}{\rho_{\mathrm{i}} L_{\mathrm{m}}^{\mathrm{ef}}\left\{\ln \left[\frac{T_{0}}{T} S_{\mathrm{w}}^{G} \exp \left(-\frac{A_{\rho} \Delta p+2 \sigma_{\mathrm{sa}} / r_{\mathrm{d}}}{\rho_{\mathrm{i}} L_{\mathrm{m}}^{\mathrm{ef}}}\right)\right]\right\}}
$$

$$
\begin{aligned}
\Delta F_{\mathrm{cr}}= & \frac{4}{3} \pi \sigma_{\mathrm{is}} r_{\mathrm{cr}}^{2}= \\
& \frac{16 \pi}{3} \frac{\sigma_{\mathrm{is}}^{3}}{\left\{\rho_{\mathrm{i}} L_{\mathrm{m}}^{\mathrm{ef}} \ln \left[\frac{T_{0}}{T} S_{\mathrm{w}}^{G} \exp \left(-\frac{A_{\rho} \Delta p+2 \sigma_{\mathrm{sa}} / r_{\mathrm{d}}}{\rho_{\mathrm{i}} L_{\mathrm{m}}^{\mathrm{ef}}}\right)\right]\right\}^{2}}
\end{aligned}
$$

We consider first the case of homogeneous nucleation for variable pressure and chemical composition. Then the preexponential factor $C_{\text {hom }}$ in eq 3.1 is ${ }^{5}$

$$
C_{\text {hom }}(T)=2 N_{\mathrm{c}}\left(\frac{\rho_{\mathrm{w}}}{\rho_{\mathrm{i}}} \frac{k T}{h}\right)\left(\frac{\sigma_{\mathrm{is}}}{k T}\right)^{1 / 2}
$$

where $h$ is Planck's constant and $N_{\mathrm{c}}$ is the number of molecules in contact with a unit area of ice surface. Using eqs 3.1 and 3.6, we can write

$$
\begin{aligned}
\Delta F_{\mathrm{cr}}= & -k T \ln \frac{J_{\mathrm{hom}}}{C_{\mathrm{hom}}}-\Delta F_{\text {act }}= \\
& \frac{16 \pi}{3} \frac{\sigma_{\mathrm{is}}^{3}}{\left\{\rho_{\mathrm{i}} L_{\mathrm{m}}^{\mathrm{ef}} \ln \left[\frac{T_{0}}{T} S_{\mathrm{w}}^{\mathrm{G}} \exp \left(-\frac{A_{\rho} \Delta p+2 \sigma_{\mathrm{sa}} / r_{\mathrm{d}}}{\rho_{\mathrm{i}} L_{\mathrm{m}}^{\mathrm{ef}}}\right)\right]\right\}^{2}}
\end{aligned}
$$

Solving for $T$, we obtain an equation for the critical temperature of homogeneous freezing 


$$
\begin{aligned}
& T_{\text {f,hom }}(\Delta p)=T_{0} S_{\mathrm{w}}^{G(T)} \exp \left[-\frac{1}{\rho_{\mathrm{i}} L_{\mathrm{m}}^{\mathrm{ef}}}\left(\frac{\Delta \rho \Delta p}{\rho_{\mathrm{w}}}+\frac{2 \sigma_{\mathrm{sa}}}{r_{\mathrm{d}}}\right)\right] \times \\
& \quad \exp \left\{-\frac{1}{L_{\mathrm{m}}^{\text {ef }} \rho_{\mathrm{i}}}\left[-\frac{16 \pi}{3} \frac{\sigma_{\mathrm{is}}^{3}}{k T \ln \left(J_{\text {hom }} / C_{\mathrm{hom}}\right)+\Delta F_{\text {act }}}\right]^{1 / 2}\right\}
\end{aligned}
$$

where $L_{\mathrm{m}}^{\mathrm{ef}}, \rho_{\mathrm{i}}, C_{\mathrm{hom}}, \sigma_{\mathrm{is}}$, and $\Delta F_{\text {act }}$ are functions of temperature and should be evaluated at the same values of $T_{\mathrm{f}, \mathrm{hom}}$ as on the left-hand side of eq 3.9. An equation follows from eq 3.9

$$
\frac{\mathrm{d} T_{\mathrm{f}, \text { hom }}}{\mathrm{d} p}=-\frac{\Delta \rho T_{\mathrm{f}, \mathrm{hom}}}{\rho_{\mathrm{w}} \rho_{\mathrm{i}} L_{\mathrm{m}}^{\mathrm{ef}}}
$$

that formally resembles the Clapeyron equation valid for melting transition in a one-component system ${ }^{5,9}$ but is derived here for freezing with finite nucleation rate and a multicomponent system. For the particular case of constant external pressure $(\Delta p=0)$ and large drops $\left(r_{\mathrm{d}} \rightarrow \infty\right)$, the first exponent on the right-hand side of eq 3.9 vanishes. For pure water drops, $S_{\mathrm{w}}=$ 1 , and only nucleation rate in the last exponent regulates $T_{\mathrm{f} \text {,hom }}$. For solutions $S_{\mathrm{w}}<1$, this leads to the lowering of $T_{\mathrm{f} \text {,hom }}$ as shown in the next section.

3.2. Volume Heterogeneous and Surface Quasi-Heterogeneous Freezing. For the case of volume heterogeneous freezing of an ice crystal, the heterogeneous nucleation rate is described by eq 3.1, where the normalizing factor for heterogeneous freezing on the surface of an aerosol particle with radius $r_{\mathrm{N}}$ is 1,5

$$
C_{\text {het }} \approx(k T / h) c_{1 \mathrm{~s}} 4 \pi r_{\mathrm{N}}^{2}
$$

where $c_{1 \mathrm{~s}}$ is the concentration of water molecules adsorbed on $1 \mathrm{~cm}^{-2}$ of a surface. Solving eq 3.1 for a heterogeneous process we obtain

$$
\Delta F_{\mathrm{cr}}=-k T \ln \frac{J_{\text {het }}}{C_{\text {het }}}-\Delta F_{\text {act }}
$$

Now, equating eq 3.11 to eq 3.3 for $\Delta F_{\mathrm{cr}}$ and solving for $T$, we obtain the volume heterogeneous freezing temperature

$$
\begin{gathered}
T_{\mathrm{f}, \text { het }}(\Delta p)=T_{0} S_{\mathrm{w}}^{G(T)} \exp \left[-\frac{1}{\rho_{\mathrm{i}} L_{\mathrm{m}}^{\mathrm{ef}}}\left(\frac{\Delta \rho \Delta p}{\rho_{\mathrm{w}}}+\frac{2 \sigma_{\mathrm{sa}}}{r_{\mathrm{d}}}+C_{\epsilon} \epsilon^{2}\right)\right] \times \\
\exp \left\{-\frac{1}{L_{\mathrm{m}}^{\text {ef }} \rho_{\mathrm{i}}}\left[-\frac{16 \pi}{3} \frac{\sigma_{\mathrm{is}}^{3} f\left(m_{\mathrm{is}}, x\right)}{k T \ln \left(J_{\text {het }} / C_{\text {het }}\right)+\Delta F_{\text {act }}}\right]^{1 / 2}\right\}
\end{gathered}
$$

When a solid is incompletely wettable by its own melt with the contact angle $\theta_{\text {is, }}$, surface freezing in the absence of the foreign substances can be considered as a quasi-heterogeneous nucleation of an ice germ at the drop surface. Then the critical free energy of an ice germ at the liquid/air interface can be written as in Defay et al., ${ }^{3}$ which using eq 2.14 for $r_{\text {cr }}$ becomes

$$
\Delta F_{\mathrm{cr}}=\frac{4}{3} \pi \sigma_{\mathrm{ia}} r_{\mathrm{cr}}^{2} f\left(m_{\mathrm{is}}, x\right)=\frac{16 \pi}{3} \frac{\sigma_{\mathrm{ia}}^{3} f\left(m_{\mathrm{is}}, x\right)}{\left\{\rho_{\mathrm{i}} L_{\mathrm{m}}^{\mathrm{ef}} \ln \left[\frac{T_{0}}{T} S_{\mathrm{w}}^{\mathrm{G}} \exp \left(-H_{\mathrm{s}, \mathrm{fr}}\right)\right]\right\}^{2}}
$$

where $f\left(m_{\mathrm{is}}\right)$ and $H_{\mathrm{s}, \mathrm{fr}}$ are defined by eqs 3.4 and 2.15 , and $m_{\mathrm{is}}$ is the cosine of the contact angle $\theta_{\text {is }}$ between ice and its own liquid (water or aqueous solution). Equating eq 3.13 to eq 3.11 for $\Delta F_{\text {cr }}$ and solving for $T$, we obtain the surface freezing temperature

$$
\begin{aligned}
T_{\mathrm{s}, \mathrm{fr}}(\Delta p)=T_{0} S_{\mathrm{w}}^{G(T)} \exp \left[-\frac{1}{\rho_{\mathrm{w}} L_{\mathrm{m}}^{\mathrm{ef}}}\left(\frac{\Delta p \Delta \rho}{\rho_{\mathrm{i}}}-\frac{2 \sigma_{\mathrm{sa}}}{r_{\mathrm{d}}}\right)\right] \times \\
\quad \exp \left\{-\frac{1}{L_{\mathrm{m}}^{\mathrm{ef}} \rho_{\mathrm{i}}}\left[-\frac{16 \pi}{3} \frac{\sigma_{\mathrm{ia}}^{3} f\left(m_{\mathrm{is}}, x\right)}{k T \ln \left(J_{\mathrm{s}, \mathrm{fr}} / C_{\mathrm{s}, \mathrm{fr}}\right)+\Delta F_{\mathrm{act}}}\right]^{1 / 2}\right\}
\end{aligned}
$$

where $J_{\mathrm{s}, \mathrm{fr}}$ and $C_{\mathrm{s}, \mathrm{fr}}$ are the nucleation rate and normalizing factor for surface freezing; their exact appearance is not important for us now for the reason explained below.

3.3. Surface Melting. For incomplete wettability, a particular case of surface melting considered here is a quasi-heterogeneous process of a liquid germ nucleation on the surface of a crystal. The critical free energy for the type of surface melting considered here can be written as for the solid/air interface ${ }^{3}$ and using eq 2.19 for $r_{\mathrm{d}}$ as

$$
\begin{aligned}
& \Delta F_{\mathrm{cr}}=\frac{4}{3} \pi \sigma_{\mathrm{sa}} r_{\mathrm{d}}^{2} f\left(m_{\mathrm{is}}, x\right)= \\
& \frac{16 \pi}{3} \frac{\sigma_{\mathrm{s} a}^{3} f\left(m_{\mathrm{is}}, x\right)}{\left\{-\rho_{\mathrm{w}} L_{\mathrm{m}}^{\mathrm{ef}} \ln \left[\frac{T_{0}}{T} S_{\mathrm{w}}^{G} \exp \left(-H_{\mathrm{m}}\right)\right]\right\}^{2}}
\end{aligned}
$$

where $f\left(m_{\mathrm{is}}\right)$ and $H_{\mathrm{m}}$ are defined by eqs 3.4 and 2.20 and $m_{\mathrm{is}}$ is again the cosine of the contact angle between ice and its own liquid. Equating eq 3.11 to 3.15 for $\Delta F_{\text {cr }}$ and solving for $T$, we obtain the melting temperature

$$
\begin{aligned}
& T_{\mathrm{m}}(\Delta p)=T_{0} S_{\mathrm{w}}^{G(T)} \exp \left[-\frac{1}{\rho_{\mathrm{i}} L_{\mathrm{m}}^{\mathrm{ef}}}\left(\frac{\Delta p \Delta \rho}{\rho_{\mathrm{w}}}+\frac{2 \sigma_{\mathrm{ia}}}{r_{\mathrm{cr}}}\right)\right] \times \\
& \exp \left\{\frac{1}{L_{\mathrm{m}}^{\text {ef }} \rho_{\mathrm{w}}}\left[-\frac{16 \pi}{3} \frac{\sigma_{\mathrm{is}}^{3} f\left(m_{\mathrm{is}}, x\right)}{k T \ln \left(J_{\mathrm{s}, \mathrm{m}} / C_{\mathrm{s}, \mathrm{m}}\right)+\Delta F_{\mathrm{act}}}\right]^{1 / 2}\right\}
\end{aligned}
$$

where $J_{\mathrm{s}, \mathrm{m}}$ and $C_{\mathrm{s}, \mathrm{m}}$ are the nucleation rate and normalizing factor for surface melting. For complete wettability $\theta_{\mathrm{is}}=0, m_{\mathrm{is}}=1$, $f\left(m_{\mathrm{is}}=1\right)=0$, and $\Delta F_{\mathrm{cr}}=0$, there is no energy barrier for nucleation. For ice surface freezing or melting, $\theta_{\text {is }}$ is nonzero but very small, ${ }^{60-63} \theta_{\text {is }} \approx 0.5-2^{\circ}$ and $f\left(m_{\text {is }}\right) \rightarrow 0$, the arguments in the second exponents in eqs 3.14 and 3.16 tend to zero, and the exponents tend to 1 . Then the expressions for the surface freezing and melting temperatures are simplified

$$
\begin{gathered}
T_{\mathrm{s}, \mathrm{fr}}\left[f\left(m_{\mathrm{is}}\right) \rightarrow 0\right]=T_{0} S_{\mathrm{w}}^{G(T)} \exp \left[-\frac{1}{\rho_{\mathrm{w}} L_{\mathrm{m}}^{\mathrm{eff}}}\left(\frac{\Delta p \Delta \rho}{\rho_{\mathrm{i}}}-\frac{2 \sigma_{\mathrm{sa}}}{r_{\mathrm{d}}}\right)\right] \\
T_{\mathrm{m}}\left[f\left(m_{\mathrm{is}}\right) \rightarrow 0\right]=T_{0} S_{\mathrm{w}}^{G(T)} \exp \left[-\frac{1}{\rho_{\mathrm{i}} L_{\mathrm{m}}^{\mathrm{ef}}}\left(\frac{\Delta \rho \Delta p}{\rho_{\mathrm{w}}}+\frac{2 \sigma_{\mathrm{ia}}}{r_{\mathrm{cr}}}\right)\right]
\end{gathered}
$$

These expressions do not depend on $J_{\mathrm{h}}$ and $C_{\mathrm{h}}$, owing to the small contact angle between water and ice. For substances when $\theta_{\text {is }}$ is not so small (e.g., some metals ${ }^{15,62,63}$ ), eqs 3.14 and 3.16 should be used, and the last exponent can make contributions lowering $T_{\mathrm{s} \text {,fr }}$ and raising $T_{\mathrm{m}}$. Equation 3.18 allows for a simple calculation of the melting point depression with increasing pressure. Differentiating eq 3.18 by $p$, we obtain

$$
\frac{\mathrm{d} T_{\mathrm{m}}}{\mathrm{d} p}=-\frac{\Delta \rho T_{0}}{\rho_{\mathrm{i}} \rho_{\mathrm{w}} L_{\mathrm{m}}^{\mathrm{ef}}} S_{\mathrm{w}}^{G(T)} \exp \left[-\frac{1}{\rho_{\mathrm{i}} L_{\mathrm{m}}^{\mathrm{ef}}}\left(\frac{\Delta \rho \Delta p}{\rho_{\mathrm{w}}}+\frac{2 \sigma_{\mathrm{ia}}}{r_{\mathrm{cr}}}\right)\right]
$$


For a particular case of bulk pure ice $\left(r_{\mathrm{cr}} \rightarrow \infty, S_{\mathrm{w}}=1\right)$, eq 3.19 is simplified and converts into the Clapeyron equation used for explanation of the dependence $T_{\mathrm{m}}(p)$ near the triple point, ${ }^{6}$ $T_{0}=273.15 \mathrm{~K}$, and yields $\mathrm{d} T_{\mathrm{m}} / \mathrm{d} p=-1 / 138 \mathrm{~K} \mathrm{~atm}^{-1}$, close to the experimental values..$^{5,6,15}$

3.4. Liquidus Curves. Equations 3.17 and 3.18 for $T_{\mathrm{s}, \mathrm{fr}}$ and $T_{\mathrm{m}}$ at $\Delta p=0$ and large $r_{\mathrm{d}}$ and $r_{\mathrm{cr}}$ or bulk solutions are reduced to

$$
\begin{array}{r}
T_{\mathrm{s}, \mathrm{rr}}(\Delta p=0)=T_{\mathrm{m}}(\Delta p=0)=T_{0} S_{\mathrm{w}}^{G(T)}=T_{0} S_{\mathrm{w}}^{R T / M_{\mathrm{w}} L_{\mathrm{m}}{ }^{\mathrm{ef}}}= \\
T_{0} a_{\mathrm{w}}^{R T / M_{\mathrm{w}} L_{\mathrm{m}}{ }^{\mathrm{ef}}}
\end{array}
$$

which indicates the reversibility of slow surface freezing and melting. Equation 3.20 is nonlinear in solution concentration and is valid not only for dilute solutions but for all concentrations. It describes liquidus curves with high accuracy over a wide range of solution concentration, as will be illustrated in section 4 . For the particular case of a dilute solution, $S_{w} \approx 1-$ $X_{\mathrm{s}}$, with $X_{\mathrm{s}}$ being the mole fraction, and expanding eq 3.20 in power series, $T_{\mathrm{s}, \mathrm{fr}}$ can be presented in a linear approximation as

$$
\begin{gathered}
T_{\mathrm{s}, \mathrm{fr}}=T_{0}\left(1-X_{\mathrm{s}}\right)^{G} \approx T_{0}-G T_{0} X_{\mathrm{s}} \approx T_{0}+m_{1} X_{\mathrm{s}} \\
m_{1}=-R_{\mathrm{v}} T_{0}{ }^{2} / L_{\mathrm{m}}=-103.1 \mathrm{~K}
\end{gathered}
$$

where eq 2.7 is used for $G$ and $m_{1}$ is a slope of the liquidus curve. Equation 3.20a is a known linear approximation for the liquidus $9,15,16$ or for the ideal freezing point depression. Note that the difference between $T_{\mathrm{s}, \mathrm{fr}}$ and $T_{\mathrm{m}}$ for ice may be caused by the small values of the segregation coefficient $k_{\mathrm{s}}$ (ratio of amount of salt trapped in ice on freezing to amount in solution), which is typically $5,9,15 \sim 10^{-6}$ to $10^{-4}$, although the amount of salt trapped on seawater freezing in the Arctic can be as high as 14 practical salinity units ( $\mathrm{psu}$ ) due to entrapped brine pockets, ${ }^{9}$ almost half of the salt concentration in the upper ocean, ${ }^{9} 30$ psu.

3.5 Freezing and Melting Point Depressions. The freezing and the melting point depressions, $\Delta T_{\mathrm{f}, \mathrm{hom}}$ and $\Delta T_{\mathrm{m}}$, and their relation are often given as $^{21-27,32,39,47-54,55}$

$$
\begin{gathered}
\Delta T_{\mathrm{f}, \mathrm{hom}}=\lambda \Delta T_{\mathrm{m}} \\
\Delta T_{\mathrm{f}, \mathrm{hom}}=T_{0}-T_{\mathrm{f} 0}-T_{\mathrm{f}}, \quad \Delta T_{\mathrm{m}}=T_{0}-T_{\mathrm{m}}
\end{gathered}
$$

where $T_{\mathrm{f} 0}=38 \mathrm{~K}$ (spontaneous freezing is assumed to start around $-38{ }^{\circ} \mathrm{C}$, or $T_{0}-T_{\mathrm{f} 0}=235 \mathrm{~K}$ which is therefore a reference point for the freezing depression) and $T_{\mathrm{f}, \mathrm{hom}}$ and $T_{\mathrm{m}}$ are evaluated from experimental data on freezing and melting. The definition of $\lambda$ from eq 3.21a is an empirical relation, and the value of $\Delta T_{\mathrm{f} \text {,hom }}$ required for numerical cloud models or analysis of the laboratory experiments is taken usually from experimental data ${ }^{55,56}$ on $\Delta T_{\mathrm{m}}$, and the average $\lambda=1.7$ is often used. ${ }^{21-27,32,39}$ We can now calculate $\lambda$ from the theory as

$$
\lambda(T)=\frac{T_{0}-T_{\mathrm{f} 0}-T_{\mathrm{f}, \mathrm{hom}}\left(S_{\mathrm{w}}, r_{\mathrm{d}}\right)}{T_{0}-T_{\mathrm{m}}\left(S_{\mathrm{w}}\right)}
$$

where $T_{\mathrm{f}, \text { hom }}$ and $T_{\mathrm{m}}$ are evaluated from eqs 3.9 and 3.20 .

\section{Comparison with Observations of Melting and Freezing Temperatures}

The equations derived in section 3 represent $T_{\mathrm{f}}$ and $T_{\mathrm{m}}$ as functions of $S_{\mathrm{w}}$ and nucleation rates $J_{\text {hom }}$ and $J_{\text {het }}$. These equations contain several functions of $T_{\mathrm{f}}$ or $T_{\mathrm{m}}$ on the righthand side; they are transcendental algebraic equations and can be solved using an iterative procedure. Numerical tests show that two to three iterations provide a convergent solution. Calculation of $T_{\mathrm{f}}$ and $T_{\mathrm{m}}$ requires data on the temperature dependence of the melting heat $L_{\mathrm{m}}(T)$ or $L_{\mathrm{m}}^{\mathrm{ef}}(T), \Delta F_{\text {act }}$, water and ice densities, and data on the temperature and composition dependence of the surface tensions. These data remain uncertain, especially at $T_{\mathrm{c}}$ below $-38{ }^{\circ} \mathrm{C}$, due to the difficulties of measurements at these temperatures. ${ }^{1-6,9,21,22,27-30,38-44,74}$ It was emphasized in a recent international Cirrus Parcel Model Comparison Project $(\mathrm{CPMCP})^{39}$ that seldom are all of the quantities available from direct measurements for a given solution. Typically, direct data for one to two parameters are used, and the others are inferred from measurements of the nucleation rates or freezing temperatures. One of the most successful recent attempts to reproduce experimental data on sulfuric acid solution drops freezing at low temperatures ${ }^{47,48}$ was performed by Tabazadeh et al., ${ }^{30,43}$ where fits were found for $L_{\mathrm{m}}(T)$ and $\sigma_{\mathrm{is}}\left(T, X_{\mathrm{S}}\right)$.

Here, we adopt a similar method. First, choosing the data on $L_{\mathrm{m}}(T)$ that is very similar in different sources, ${ }^{2,43,74}$ we approximate it as $L_{\mathrm{m}}(T)=c_{\mathrm{L}} T\left[\tanh \left(T-T_{1}\right) / T_{2}+1.6\right]$; the best fit down to $160 \mathrm{~K}$ was found with $T_{1}=215 \mathrm{~K}, T_{2}=40 \mathrm{~K}, c_{\mathrm{L}}$ $=8.82$, where $L_{\mathrm{m}}$ is in cal g $\mathrm{g}^{-1}$ and $T$ is in $\mathrm{K}$. This representation allows integration over $T$ to obtain the effective $L_{\mathrm{m}}^{\mathrm{ef}}(T)$ defined after eq 2.5. The values of $\sigma_{\mathrm{sa}}$ were determined by using data ${ }^{30,43}$ with subsequent tuning in order to obtain the best agreement for $T_{\mathrm{f}}$ over the entire temperature range. The best fits were for ammonium sulfate, $\sigma_{\mathrm{sa}}=143.8-0.249 T-0.97 w+3.4 \times$ $10^{-2}(T w)-3.5 \times 10^{-5}\left(w^{3}\right)$, and for sulfuric acid, $\sigma_{\mathrm{sa}}=137.56$ $-0.225 T-0.98 w+3.395 \times 10^{-2}(T w)-5.1 \times 10^{-5}\left(w^{2}\right)-$ $1.24 \times 10^{-4}\left(w^{3}\right)$, where $\sigma_{\mathrm{sa}}$ is in ergs, $T$ in $\mathrm{K}$, and $w$ is the percentage concentration by weight. The values of $\sigma_{\text {is }}$ were calculated from Antonoff's rule ${ }^{5,43}$ with $\sigma_{\mathrm{ia}}=105 \mathrm{erg} \mathrm{cm}^{-2}$; the values of $\sigma_{\text {is }}$ for pure water match the values measured by Ketcham and Hobbs. ${ }^{60}$ Numerical tests show that the values of $T_{\mathrm{f}}$ are less sensitive to the $\Delta F_{\text {act }}$. The choice ${ }^{75}$ of $\Delta F_{\text {act }}$ was satisfactory. The effects of the particle curvature on surface tensions are small ${ }^{2,5}$ in the range of sizes $\geq 0.2 \mu \mathrm{m}$ were considered in the following sections and were neglected.

Data on freezing of solution drops are contradictory. The data generally converge around $-40{ }^{\circ} \mathrm{C}$ for pure water, but values of $T_{\mathrm{f}, \text { hom }}$ diverge as solution concentration increases and $T_{\mathrm{f}, \mathrm{hom}}$ decreases. ${ }^{21,22,47-51,53,54}$ Here, we tuned the parameters to data that are in the middle of that diverging range. ${ }^{48,51,52}$ If the initial concentration of drops before freezing is $N_{0}$, then the concentrations of frozen $N_{\mathrm{f}}$ and unfrozen $N_{\mathrm{u}}$ drops are determined by the relations ${ }^{5}$

$$
N_{\mathrm{u}}=N_{0} \exp \left(-V_{\mathrm{d}} J_{\text {hom }} \tau_{\mathrm{fr}}\right), \quad N_{\mathrm{f}}=N_{0}-N_{\mathrm{u}}
$$

where $V_{\mathrm{d}}=4 /{ }_{3} \pi r_{\mathrm{d}}^{3}$ is the drop volume, $r_{\mathrm{d}}$ is the droplet radius, and $\tau_{\mathrm{fr}}$ is the characteristic "freezing time". We assumed in most calculations that $J_{\mathrm{hom}} V_{\mathrm{d}} \tau_{\mathrm{fr}}=1$ (i.e., freezing temperature $T_{\mathrm{f}}$ is defined by an e-folding decrease of $N_{0}$ during $\tau_{\text {fr }}$ ). This assumption implies that the nucleation rate is determined by $J_{\text {hom }}=\left(V_{\mathrm{d}} \tau_{\mathrm{fr}}\right)^{-1}$. It is seen from eq 4.1 that $99 \%$ of drops freeze during $4.6 \tau_{\mathrm{fr}}$. In most calculations, $\tau_{\mathrm{fr}}=1 \mathrm{~s}, r_{\mathrm{d}}$ was varied, and then $J_{\text {hom }}$ was evaluated as indicated.

For ease of comparison with observations, the results of calculations are presented as functions of water saturation ratio $S_{\mathrm{w}}$ and weight concentration $w=m_{\mathrm{s}} /\left(m_{\mathrm{s}}+m_{\mathrm{w}}\right) 100 \%$, where $m_{\mathrm{s}}$ and $m_{\mathrm{w}}$ are the masses of solute and water in solution, 

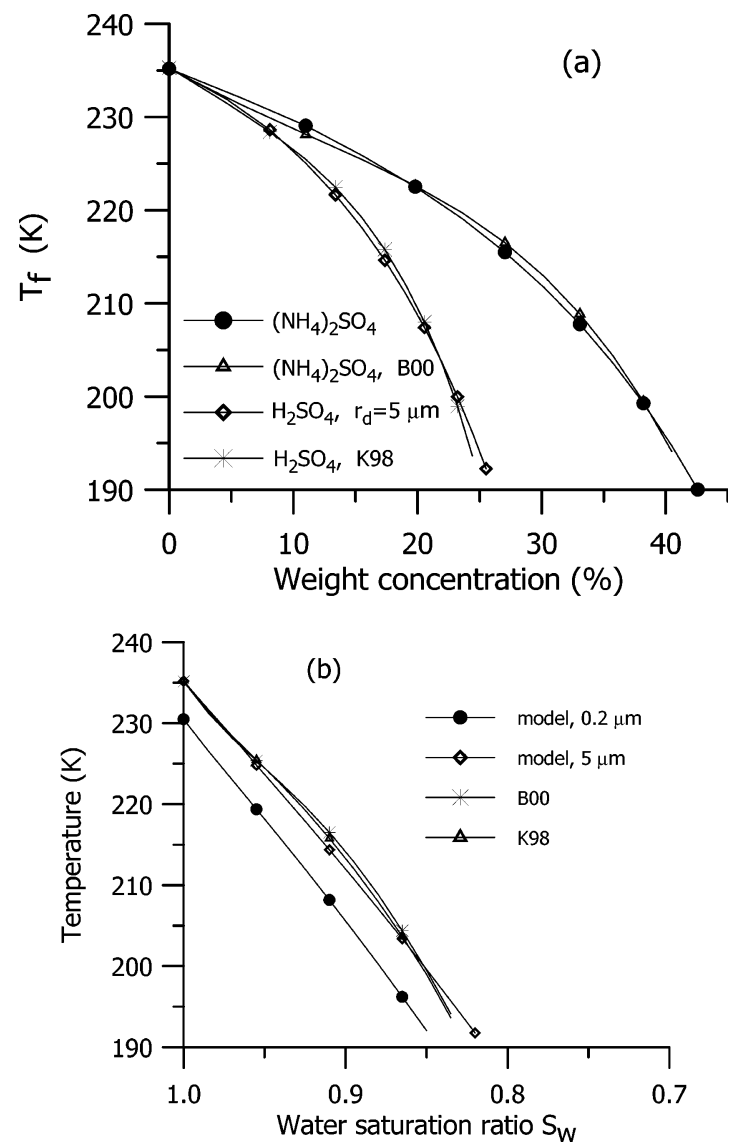

Figure 1. (a) Homogeneous freezing temperature $T_{\mathrm{f}, \text { hom }}$ as a function of the weight concentration. Calculations from eq 3.9 for solution drops of $5 \mu \mathrm{m}$ for ammonium sulfate (solid circles) compared to the parametrization from Bertram et al. ${ }^{51}$ (B00) and calculations for sulfuric acid droplets of $5 \mu \mathrm{m}$ (diamonds) compared to the parametrization from Koop et al. ${ }^{48}$ (K98). (b) Homogeneous freezing temperatures $T_{\text {f,hom }}$ as functions of water saturation ratio calculated from eq 3.9 as described in the text after second $T$ iteration for the haze drop radius $r_{\mathrm{d}}=0.2$ $\mu \mathrm{m}$ (solid circles) and for $r_{\mathrm{d}}=5 \mu \mathrm{m}$ (diamonds), parametrizations of Bertram et al. ${ }^{51}$ for $T_{\mathrm{f}, \mathrm{hom}}$ of ammonium sulfate (asterisks, B00), and of Koop et al. ${ }^{48}$ for sulfuric acid (triangles, K98) recalculated from their weight concentrations to $S_{\mathrm{w}}$.

respectively. Water saturation ratios and activities were related to $w$ and molality $\hat{M}$ using the usual relation ${ }^{5,21} \hat{M}=10 w /\left[M_{\mathrm{s}} /\right.$ (1 $-w / 100)$ ], with $M_{\mathrm{s}}$ being the molecular weight, and parametrizations of $a_{\mathrm{w}}$ via $\hat{M}$ or $w$ for ammonium sulfate, ${ }^{76}$ sulfuric acid, ${ }^{32,77}$ and $\mathrm{NaCl} .^{9,79}$

The homogeneous freezing temperature $T_{\mathrm{f}, \text { hom }}$ for $p=1$ atm is presented in Figure 1. Calculations were performed using eq 3.9 for sulfuric acid $\left(M_{\mathrm{s}}=98\right)$ and ammonium sulfate $\left(M_{\mathrm{s}}=\right.$ 132), $\tau_{\mathrm{f} r}=1 \mathrm{~s}$, and for the solution drop radii $r_{\mathrm{d}}=5 \mu \mathrm{m}$ and $0.2 \mu \mathrm{m}$. Figure 1 shows that the values of $T_{\mathrm{f}}$ for pure water $(w$ $\left.=0, S_{\mathrm{w}}=1\right)$ are $231 \mathrm{~K}\left(-42{ }^{\circ} \mathrm{C}\right)$ for $r_{\mathrm{d}}=0.2 \mu \mathrm{m}$ and 235.2 $\mathrm{K}\left(-38{ }^{\circ} \mathrm{C}\right)$ for $r_{\mathrm{d}}=5 \mu \mathrm{m}$. Thus, eq 3.9 along with the fits for the parameters described above yields the well-known temperatures near $-40{ }^{\circ} \mathrm{C}$, typically referred to as "the temperature of spontaneous freezing of pure water drops". ${ }^{1-6}$ Calculated variation of $T_{\mathrm{f} \text {,hom }}$ with $w$, being in excellent agreement with parametrizations of laboratory data, ${ }^{48,51}$ depends on the chemical nature of the solute (Figure 1a).

However, Figure 1b shows that $T_{\mathrm{f}, \mathrm{hom}}\left(S_{\mathrm{w}}\right)$ exhibits colligative properties, whereby the curves for ammonium sulfate and sulfuric acid for $r_{\mathrm{d}}=5 \mu \mathrm{m}$ almost coincide and merge with the experimental parametrizations presented here as functions of $S_{\mathrm{w}}$. This is in agreement with the results showing experimental
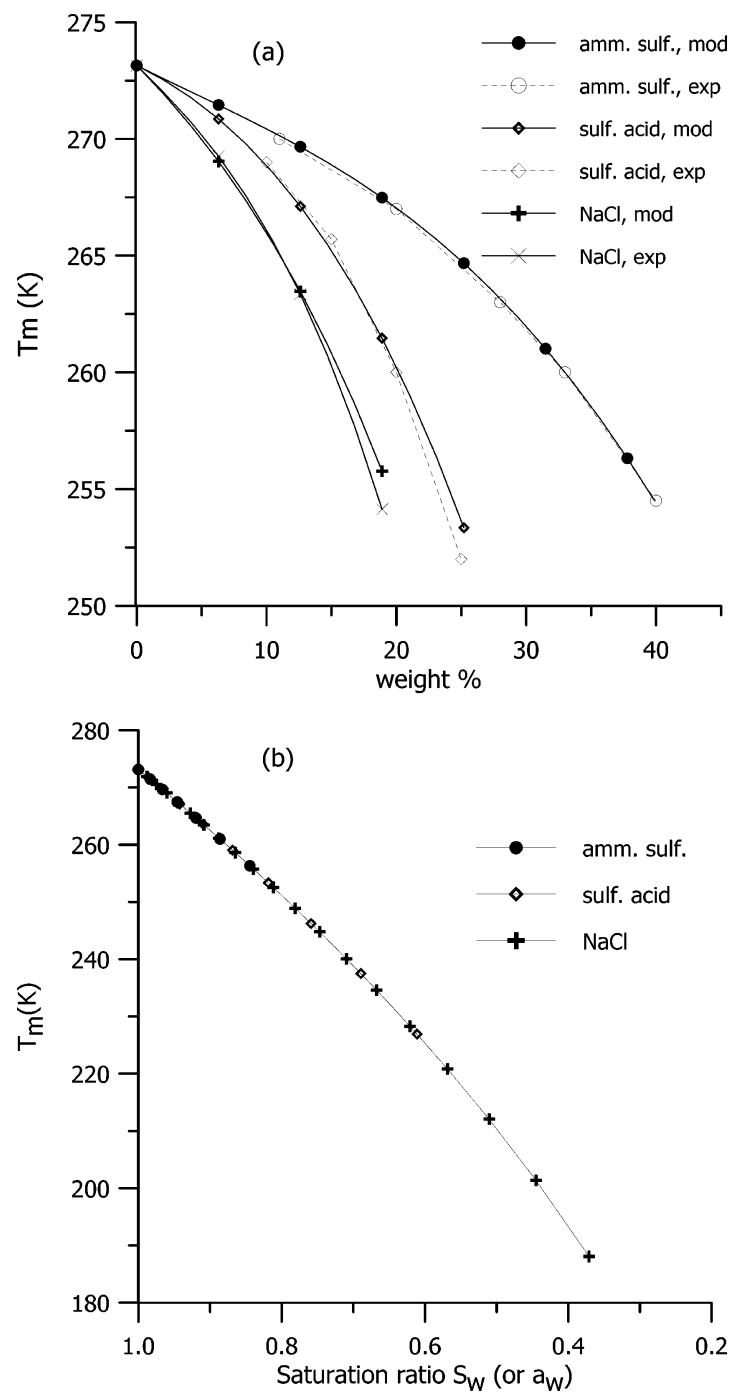

Figure 2. (a) Melting temperatures as functions of weight $\%$, calculated (labeled "mod") from eq 3.20 for ammonium sulfate (closed circles), sulfuric acid (closed diamonds), and $\mathrm{NaCl}$ (crosses), compared to the corresponding experimental data (labeled "exp"). Saturation ratio $S_{\mathrm{w}}$ is assumed to be equal to water activity, which is calculated for ammonium sulfate with eqs from Tang and Munkelvitz ${ }^{76}$ and for sulfuric acid from Chen ${ }^{77}$ and DeMott et al. ${ }^{32}$ Experimental data on $T_{\mathrm{m}}$ for ammonium sulfate and sulfuric acid are taken from corresponding figures in DeMott. ${ }^{22}$ The experimental parametrization of $T_{\mathrm{m}}(s)$ for $\mathrm{NaCl}$ as a function of salt concentration $s$ (psu) is taken from Curry and Webster $^{9}$ and Millero ${ }^{79}$ and recalculated from $s$ to water activity. (b) The same $T_{\mathrm{m}}$ calculated with eq 3.20 as in Figure 2a, but recalculated from the weight percent to water activity (or saturation ratio).

data on $T_{\text {f,hom }}$ for 18 substances $^{52 \mathrm{a}}$ and for several alkali halides ${ }^{78}$ that, being plotted as a function of water activity $\left(a_{\mathrm{w}} \approx S_{\mathrm{w}}\right)$, lie nearly on the same curve, ${ }^{52}$ and with the explanation of this fact with the water-activity-based theory of homogeneous ice nucleation by Koop et al. ${ }^{52}$ Figure $1 \mathrm{~b}$ shows that the decrease in $r_{\mathrm{d}}$ from 5 to $0.2 \mu \mathrm{m}$ results in a decrease of $T_{\mathrm{f} \text {,hom }}$ by $4 \mathrm{~K}$, which is also in agreement with experimental data. ${ }^{1,4,5,45} T_{\mathrm{f}, \mathrm{hom}}$ calculated for $r_{\mathrm{d}}=0.2 \mu \mathrm{m}$ lies lower as a whole, which can contribute to the residual difference for polydispersed drop spectra (seemingly noncolligative, i.e., depending not only on $\left.S_{\mathrm{w}}\right)$.

Similar calculations with eq 3.20 of the melting temperature $T_{\mathrm{m}}$ or surface freezing temperature $T_{\mathrm{s} \text {,fr }}$ (liquidus curves) at $p$ $=1 \mathrm{~atm}$ for ammonium sulfate, sulfuric acid, and $\mathrm{NaCl}$ are shown in Figure 2, again exhibiting a good agreement with experimental data. Note that these results do not depend on 
surface tension or droplet radius and weakly depend on the melting heat in the considered range. Again, the results as a function of weight concentration $w$ differ for the three indicated chemical species (Figure 2a) but merge as a function of $S_{\mathrm{w}}$, exhibiting a colligative property of $T_{\mathrm{m}}$ (Figure 2b), in agreement with Koop et al.52a,b Thus, Figure 2 shows that eq 3.20 can be used with sufficient accuracy for calculations of $T_{\mathrm{m}}$ for standard pressure.

One of the most interesting and important applications of this theory is calculation of the freezing and melting point depressions, $\Delta T_{\mathrm{f}, \text { hom }}$ and $\Delta T_{\mathrm{m}}$, and their ratio, $\lambda$, which is used in cloud models. Measured values of $\Delta T_{\mathrm{f}, \mathrm{hom}}$ and $\Delta T_{\mathrm{m}}$ for micron-sized drops for several substances exhibit a linear relation. ${ }^{55}$ It was hypothesized $^{55}$ that this is in conflict with classical nucleation theory, and it could be explained by the relation of thermodynamic and kinetic processes and by spinodal decomposition in ice formation of aqueous electrolytes. This conjecture was challenged by Martin ${ }^{21}$ who stressed that an explanation of this relation remains an open question. At present, the nature and magnitude of $\lambda$ still remain unclear. Here we use eqs 3.9 and 3.20 to calculate $\Delta T_{\mathrm{f} \text {,hom }}$ and $\Delta T_{\mathrm{m}}$ for $r_{\mathrm{d}}=5 \mu \mathrm{m}$ with the same parameters as used for Figures 1 and 2 and then calculate $\lambda$ with eq 3.22 and compare with laboratory data 22,55 and the experimental parametrization for sulfuric acid ${ }^{48}$ (Figure 3).

To illustrate also the effect of drop radii, we have chosen the freezing threshold $T_{\mathrm{f} 0}=38 \mathrm{~K}$ in the definition eq $3.21 \mathrm{~b}$ of $\Delta T_{\mathrm{f}, \text { hom }}$ for $r_{\mathrm{d}}=5 \mu \mathrm{m}$ as it is usually done in retrievals of $\lambda$ from experimental data (Figure 1b). As seen in Figure 3a, the calculated freezing point depression exhibits a relation that looks quasi-linear on the $\Delta T_{\mathrm{f}, \text { hom }}-\Delta T_{\mathrm{m}}$ diagram. The experimental data for $T_{\mathrm{f}, \mathrm{hom}}$ lie mostly between the regression lines $\lambda=1.5$ and 2 up to $\Delta T_{\mathrm{f}} \approx 10 \mathrm{~K}$, and the curve calculated here for $r_{\mathrm{d}}=$ $5 \mu \mathrm{m}$ matches the observations. For higher values of $\Delta T_{\mathrm{f}}$ up to $\sim 45 \mathrm{~K}$, experimental data ${ }^{48}$ lie closer to $\lambda=2$ and so does the calculated curve. We can draw the following conclusions from Figure 3a: (a) classical nucleation theory is capable of describing the quasi-linear relation between the freezing and melting point depressions and can be used in cloud models for evaluation of $\lambda$ or directly for $T_{\mathrm{f}, \mathrm{hom}}$; (b) a more detailed theoretical analysis should include kinetic simulation of the freezing of a polydispersed drop ensemble (as it is done in some cloud models ${ }^{28,29,36 \mathrm{~b}, 39}$ ) because freezing proceeds from larger to smaller drop sizes and the values of $T_{\mathrm{f}, \mathrm{hom}}$ and $\lambda$ determined in experiments may depend on the fraction and size of frozen drops.

Direct calculation of the parameter $\lambda=\Delta T_{\mathrm{f}} / \Delta T_{\mathrm{m}}$ with eq 3.22 (Figure 3, parts $\mathrm{b}$ and $\mathrm{c}$ ) shows that it is not a constant because it depends on chemical composition and $S_{\mathrm{w}}$. The calculated $\lambda(w)$ for ammonium sulfate and sulfuric acid (Figure $3 b)$ depends on the chemical composition, but the curves are relatively close to each other and to the curves derived from laboratory data. ${ }^{47,48} \lambda(w)$ varies mostly between 1.9 and 2.2 , in agreement with the previous analysis of experimental data for these substances. ${ }^{22}$ When plotted as $\lambda\left(S_{\mathrm{w}}\right)$ (Figure 3c), the curves almost merge, exhibiting again colligative properties as both $\Delta T_{\mathrm{f} \text {,hom }}$ and $\Delta T_{\mathrm{m}}$ (Figures $1 \mathrm{~b}$ and $2 \mathrm{~b}$ ), in agreement with previous concepts. ${ }^{52}$ The values $\lambda\left(S_{\mathrm{w}}\right)$ are not constant but exhibit a monotonic growth with decreasing $S_{\mathrm{w}}$, and use of constant $\lambda$ in cloud models may lead to the errors in $\Delta T_{\mathrm{f}, \mathrm{hom}}$. The difference slightly increases at small $w$ or $S_{\mathrm{w}} \rightarrow 1$, but both calculations and measurements become less reliable at small solute concentrations (or $S_{\mathrm{w}} \rightarrow 1$ ) because both $\Delta T_{\mathrm{f} \text {,hom }}$ and $\Delta T_{\mathrm{m}}$ decrease and even a small error in each of these quantities may lead to an increasing error in their ratio $\lambda$.
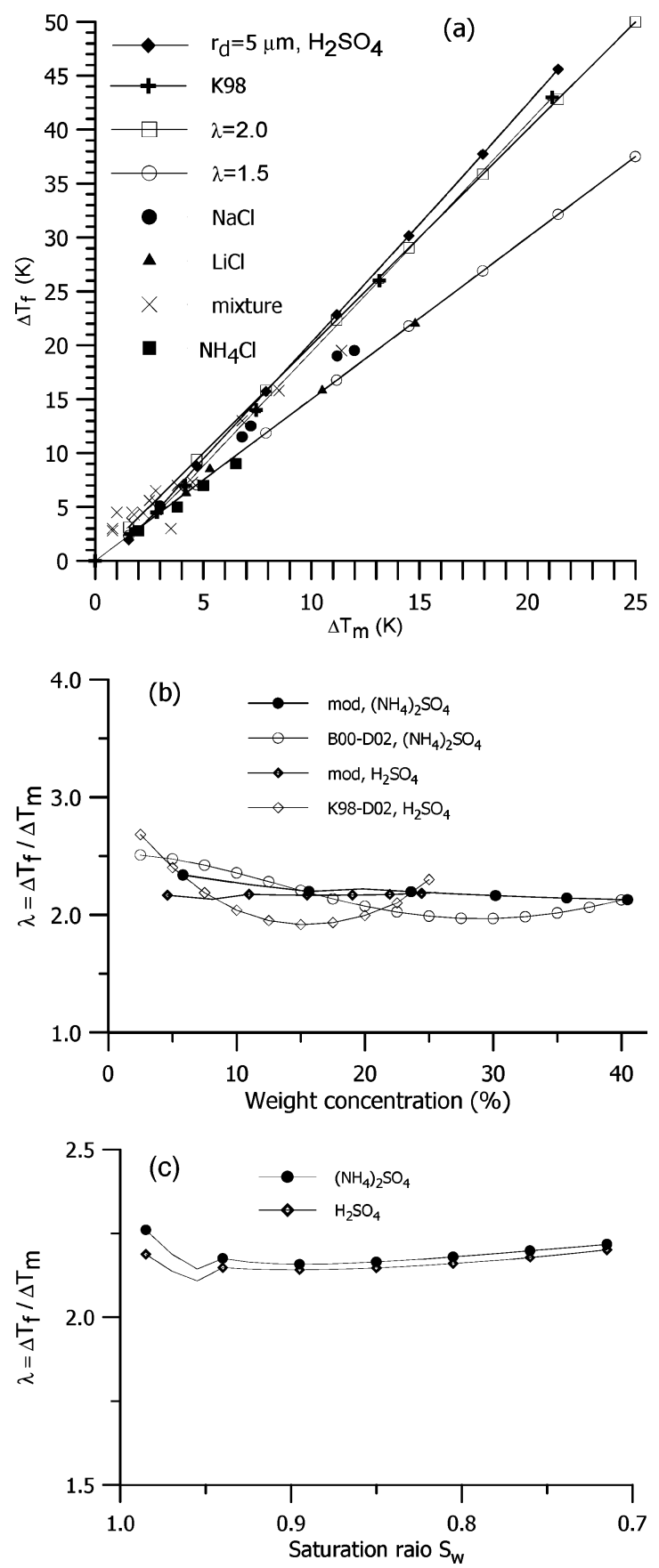

Figure 3. (a) Calculated relation $\Delta T_{\mathrm{f}}-\Delta T_{\mathrm{m}}$ for the $5 \mu \mathrm{m}$ solution droplets of sulfuric acid (diamonds) compared to the experimental data by Koop et al ${ }^{48}$ for sulfuric acid and to the experimental data compiled by DeMott; ${ }^{22}$ correlations $\lambda=\Delta T_{\mathrm{f}} / \Delta T_{\mathrm{m}}=1.5$ and $\lambda=2$ are given for comparison. (b) Parameter $\lambda(w)$ calculated with eq 3.22 for the drop radii of $5 \mu \mathrm{m}$ as a function of weight concentration for ammonium sulfate and sulfuric acid compared to $\lambda$ calculated with the experimental $T_{\text {f,hom }}$ from Koop et al. ${ }^{48}$ and DeMott ${ }^{22}$ for sulfuric acid (K98-D02) and from Bertram et al. ${ }^{51}$ and DeMott ${ }^{22}$ (B00-D02) for ammonium sulfate and with $T_{\mathrm{m}}$ shown in Figure 2. (c) $\lambda$ as a function of water saturation ratio for ammonium sulfate and sulfuric acid.

Calculations with varying $r_{\mathrm{d}}$ (not shown here) demonstrate that $\lambda$ also may depend on the drop size, because $T_{\mathrm{f} 0}$ increases with decreasing drop size $r_{\mathrm{d}}$ (recall, the threshold temperature $T_{\mathrm{f} 0} \approx 38 \mathrm{~K}$ for $r_{\mathrm{d}}=5 \mu \mathrm{m}$ and $42 \mathrm{~K}$ for $0.2 \mu \mathrm{m}$, Figure 1 ), and no single value is representative for the ensemble of drops. So, different thresholds $T_{\mathrm{f} 0}$ should be chosen for various drop radii, which illustrates a problem in the analysis of experimental data 


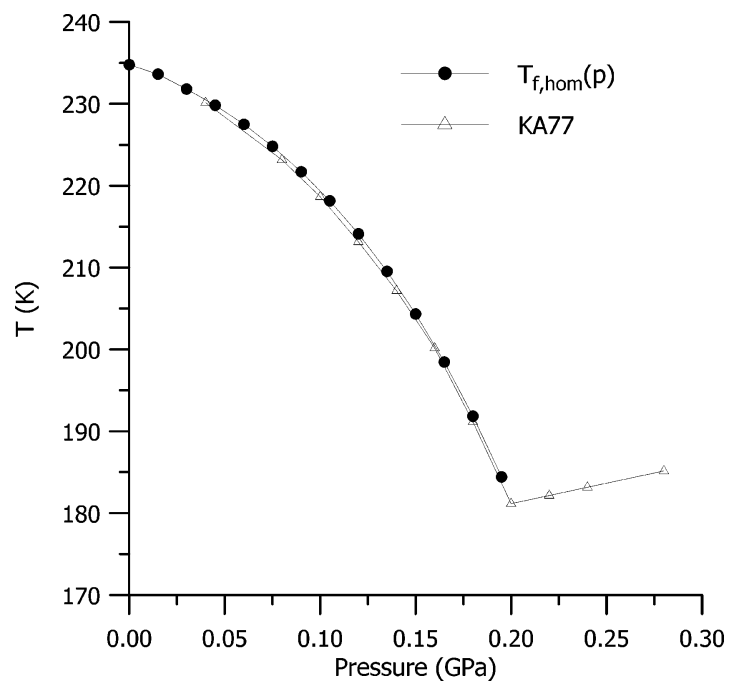

Figure 4. Homogeneous nucleation temperatures $T_{\mathrm{h} \text {,hom }}$ calculated with eq 3.9 for pure water as a function of pressure (circles) and compared to the experimental data from Kanno and Angell ${ }^{57}$ (triangles, KA77).

obtained with polydispersed drops and in the evaluation of $\lambda$ using the theory as it is done here.

A preliminary recommendation for the cloud models could be as follows: (a) if a model allows, then use directly the approaches based on the classical theory for the nucleation rates rather than the $\lambda$-approach; (b) if such calculations are too timeconsuming for a specific model, then the average values of $\lambda$ can be used, but with caution, especially in models with polydispersed drops.

\section{Comparison with Experimental Data for Variable Pressure}

Calculations of freezing and melting point temperatures under conditions of variable pressure are sensitive to variations in the density of liquid and solid water, $\rho_{\mathrm{w}}(T, p)$ and $\rho_{\mathrm{i}}(T, p)$. We use a standard parametrization ${ }^{5}$ for $\rho_{\mathrm{i}}(T)$ for ice Ih. Experimental data on $\rho_{\mathrm{w}}(T, p)$ below $T=-40{ }^{\circ} \mathrm{C}$ is scarce, and $\rho_{\mathrm{w}}(T, p)$ is taken from the equation of state for liquid water, ${ }^{75,80}$ molecular dynamics simulations, ${ }^{81-83}$ or experiment where possible. ${ }^{84} \mathrm{We}$ have used available data and, in addition, eq 3.9a to estimate variations of $\rho_{\mathrm{w}}(T, p)$ from the slopes $\mathrm{d} T_{\mathrm{f}, \mathrm{hom}} / \mathrm{d} p$ in the experimental data of Kanno and Angell ${ }^{57,58}$ for $T_{\mathrm{f} \text {,hom. We have from }}$ eq 3.9a for $\Delta \rho=\rho_{\mathrm{w}}-\rho_{\mathrm{i}}$

$$
\Delta \rho \approx-\frac{\rho_{\mathrm{w}} \rho_{\mathrm{i}} L_{\mathrm{m}}}{T_{\mathrm{f} \text {,hom }}}\left(\frac{\mathrm{d} T_{\mathrm{f}, \mathrm{hom}}}{\mathrm{d} p}\right)
$$

The results described below were obtained using referenced values ${ }^{75,80-85}$ of $\Delta \rho$ and values estimated from eq 5.1 using the corresponding data $57,58,84,85$ on $\mathrm{d} T_{\mathrm{f}, \mathrm{hom}} / \mathrm{d} p$ and $\mathrm{d} T_{\mathrm{m}} / \mathrm{d} p$.

Equation 3.9 includes the simultaneous effects of pressure and chemical composition on $T_{\mathrm{f}, \mathrm{hom}}(\Delta p)$. The effects of composition $\left(S_{\mathrm{w}}<1\right)$ at $p=$ constant were analyzed in the previous section, and now Figure 4 presents freezing temperatures $T_{\mathrm{f} \text { hom }}(p)$ calculated with eq 3.9 as a function of pressure for pure water $\left(S_{\mathrm{w}}=1\right)$. A comparison of theoretical and experimental results in Figure 4 exhibits good agreement over the entire temperature and pressure ranges, indicating the validity of eq 3.9. Note that the experimental data show the change of the sign of the slope at $p \approx 2 \mathrm{kbar}$. This is caused by the nucleation of ice III, which begins at $p \approx 1.8$ kbar and prevails ${ }^{57}$ at pressures higher than 2 kbar (a possible relatively wide temperature range of coexistence of ice I and ice III at $p=1$

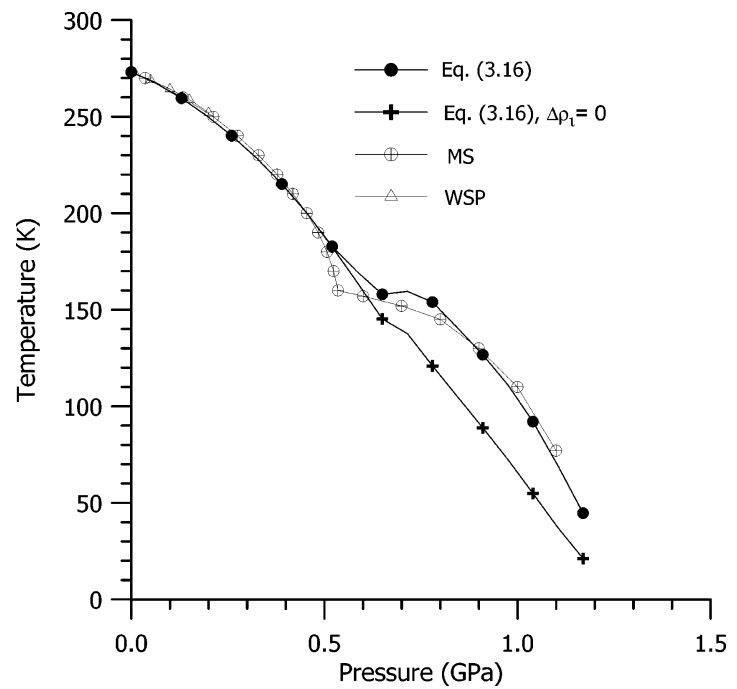

Figure 5. Melting temperature for the pressure-induced melting of ice calculated using eq 3.16 as a surface melting process with $\rho_{\mathrm{i}}(T)=$ constant (crosses) and with linear increase of ice density $\rho_{\mathrm{i}}(T)$ by 0.04 $\mathrm{g} \mathrm{cm}^{-3}$ in the range $p=0.6-0.8 \mathrm{GPa}$ (solid circles) compared to the experimental data of Mishima and Stanley ${ }^{84,85}$ down to $\sim 80 \mathrm{~K}$ (open circles, MS) and to Wagner et al. ${ }^{87}$ down to $251 \mathrm{~K}$ (triangles, WSP).

atm was explained ${ }^{86}$ by the polydispersed structure of finely dispersed ices). This transition in Figure 4 is explained simply by eqs $2.6,3.9$, and 5.1 because the pressure dependence of freezing temperature is determined by the difference $\left(\rho_{\mathrm{w}}-\rho_{\mathrm{i}}\right)$ and the density of ice III is greater ${ }^{6}$ than that of ice Ih, the slopes $\mathrm{d} T_{\mathrm{f}, \mathrm{hom}} / \mathrm{d} p$ may vary and change sign at abrupt changes of the ice densities. We do not analyze this effect here in detail, because this requires more precise data on $\rho_{\mathrm{i}}$ and $\rho_{\mathrm{w}}$.

Similar calculations were performed for pressure-induced melting ice temperature $T_{\mathrm{m}}$ using eq 3.16 for bulk ice $\left(r_{\mathrm{cr}}=\infty\right)$ and $S_{\mathrm{w}}=1$ (pure water) (calculations using eq 3.18 give similar values due to small contact angle at water-ice interface). The results are compared in Figure 5 with experimental data. ${ }^{84,85,87}$ One can see that the experimental curve ${ }^{84,85}$ has two distinct branches and the slopes change at $p \approx 0.5 \mathrm{GPa}$, which also is explained ${ }^{84,85}$ by the change near this point of ice type from hexagonal Ih to the other types of ice with higher densities (ice III or ice V). Figure 5 shows that the values of $T_{\mathrm{m}}$ calculated from eq 3.16 and 3.18 are very close to both experimental curves up to $p=0.5 \mathrm{GPa}$, but the difference between calculated and observed values increases at higher pressures with $\rho_{\mathrm{i}}(T)=$ constant. Agreement becomes a little better with a linear increase in $\rho_{\mathrm{i}}(T)$ by $0.04 \mathrm{~g} \mathrm{~cm}^{-3}$ over the range $p=0.6-0.8 \mathrm{GPa}$ (this could imitate admixture of the other denser ice ${ }^{84,85}$ ); however, the discrepancy still remains. Computer lattice dynamics simulations $^{82,83}$ determined that melting is caused by thermodynamic instability up to $p \approx 0.5 \mathrm{GPa}$ and by mechanical instability at higher pressures. Our results are consistent with this conclusion, satisfactorily describing the upper branch of the $T_{\mathrm{m}}$ curve to $p$ $\approx 0.5 \mathrm{GPa}$ but worsening for higher $p$ values. Thus eqs 3.16 and 3.18 can serve for simple calculations of $T_{\mathrm{m}}(p)$ for pure water up to $p=0.5 \mathrm{GPa}$; its predictions for pressure-induced melting with account of solutions $\left(S_{\mathrm{w}}<1\right)$ could be verified experimentally.

An interesting question on the equivalence of the pressure and solution effects on freezing and melting temperatures ${ }^{57,58,88}$ was explained by the similar effect of solution and applied pressure on the hydrogen bonding network and by showing that the plots of $T_{\mathrm{f}}\left(a_{\mathrm{w}}\right)$ and $T_{f}(p)$ are similar; this effect was described by introducing the "effective" solution concentration. ${ }^{52 a}$ A simple quantitative expression for this equivalence can be easily 


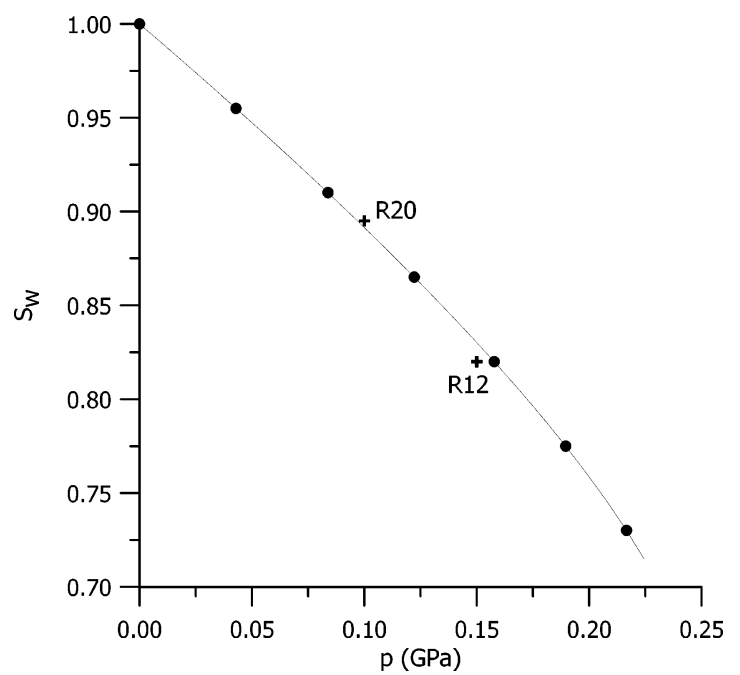

Figure 6. Equivalence of pressure and saturation ratio or molality expressed with eqs 5.2 and 5.3. Calculated curve (circles) and two points from Kanno and Angell ${ }^{57}$ (crosses) that are expressed in that work as equivalence of $p=1.0 \mathrm{kbar}(0.1 \mathrm{GPa})$ to $R=20(\hat{M}=2.75)$ and $p=$ $1.5 \mathrm{kbar}(0.15 \mathrm{GPa})$ to $R=12(\hat{M}=4.65) ; R$ is defined ${ }^{57}$ as $R=$ $\hat{M} / 55.5$.

found from eq 2.6 for $r_{\mathrm{cr}}\left(T, S_{\mathrm{w}}, p\right)$, which shows that variations in solution concentration $\left(S_{\mathrm{w}}\right)$ are equivalent to pressure variations. It is seen from eq 2.6 that this equivalence can be expressed as $S_{\mathrm{w}}^{G}=\exp \left(-H_{\mathrm{v}, \mathrm{fr}}\right)$, which is simplified for bulk solutions $\left(r_{\mathrm{d}}=\infty\right)$ and homogeneous freezing $(\epsilon=0)$ as

$$
S_{\mathrm{w}}^{G}=\exp \left(-\frac{\Delta \rho \Delta p}{\rho_{\mathrm{i}} \rho_{\mathrm{w}} L_{\mathrm{m}}^{\mathrm{ef}}}\right)
$$

Equation 5.2 expresses $S_{\mathrm{w}}$ (or equivalent molality) as a function of $p$. Solving for $\Delta p$, we obtain

$$
\Delta p=-Q \ln S_{\mathrm{w}}, \quad Q(T, p)=\frac{R T \rho_{\mathrm{i}} \rho_{\mathrm{w}}}{M_{\mathrm{w}}\left(\rho_{\mathrm{w}}-\rho_{\mathrm{i}}\right)}
$$

This equation shows that a decrease in $S_{\mathrm{w}}$ (increase in solution molality) is equivalent to an increase in $\Delta p$, with proportionality determined by the function $Q$ that depends on the densities and temperature. The proportionality is $\Delta p \sim-T \ln S_{\mathrm{w}}$ with the constant densities, although they in turn depend on $p$ and $T$. The value of $Q$ is very large, $Q \approx 10^{4}$ atm at $T \approx 273 \mathrm{~K}$ and increases with decreasing $T$ so that a saturation ratio $S_{\mathrm{w}}=0.9$ ( $\ln S_{\mathrm{W}} \approx-0.1$ ) is equivalent to a pressure of $10^{3}$ atm at $T \approx$ $273 \mathrm{~K}$. Thus, eqs 5.2 and 5.3 establish the equivalence of the distortion of the crystalline lattice by the chemical forces and mechanical pressure. This is illustrated in Figure 6, which presents the $\Delta p-S_{\mathrm{w}}$ relation calculated with eq 5.3 in the same way as the previous two figures. For comparison, we plotted also the two experimental points ${ }^{57}$ that show the equivalence of $p=1000$ bar to molality of $\mathrm{NaCl} \hat{M}=2.75(R=20)$ and $p=1500$ bar to $\hat{M}=4.65(R=12)$ for both freezing and melting temperatures (recalculated from molalities to $S_{\mathrm{w}}$ ). Figure 6 shows good agreement of the curve calculated with eq 5.3 with the experimental data and confirms the validity of these equations, which therefore can be used for the prediction of the pressure effects on $T_{\mathrm{f}, \mathrm{hom}}$ and $T_{\mathrm{m}}$ given the solution effects, or vice versa.

\section{Summary and Conclusions}

The processes of volume and surface freezing and melting of aqueous solutions are considered in the context of generalized classical nucleation theory, with the goal of improving understanding of melting and freezing processes. General equations are derived for the critical radii and energies of the ice and liquid germs that are expressed as functions of temperature $T$, water saturation ratio $S_{\mathrm{w}}$ (or solution concentration $w$ ), and external pressure $p$. The derived equations for the critical radii and energies of the ice and liquid germs can be applied to both homogeneous and heterogeneous nucleation, including variable pressure, and reduce to the traditional expressions for particular cases of homogeneous nucleation of pure water, heterogeneous nucleation, constant pressure processes, and solutions.

By use of these expressions, equations are derived for the heterogeneous, quasi-heterogeneous, and homogeneous freezing temperatures $T_{\mathrm{f}}$, whereby freezing is considered as a process of ice germ formation that occurs on the surface of the foreign particles within the volume of supercooled liquid for heterogeneous freezing, on the surface between liquid and its own solid for quasi-heterogeneous freezing, and within the bulk volume for homogeneous freezing. Similar equations are obtained for the melting temperature $T_{\mathrm{m}}$, viewing melting as a process of quasi-heterogeneous liquid germ formation on the ice crystal surface. The quantities $T_{\mathrm{f}}$ and $T_{\mathrm{m}}$ are expressed as analytical functions of external variables (water saturation ratio or solution concentration, pressure, nucleation rate, and contact angle) and on thermodynamic parameters (latent heat, interfacial surface tensions, activation energy, and densities of water and ice). The derived expressions for $T_{\mathrm{f}}$ and $T_{\mathrm{m}}$ are transcendental algebraic equations that are solved numerically using an iterative procedure, allowing simple and rapid calculation of freezing and melting temperatures over the entire range of $S_{\mathrm{w}}$ or $w$ and $p$ values.

The theory has been illustrated here by application to pure water and aqueous solutions of several substances (ammonium sulfate, sulfuric acid, and $\mathrm{NaCl}$ ); however, this method allows easy calculations for many other solutions. The theory correctly describes the decrease of $T_{\mathrm{f}}$ and $T_{\mathrm{m}}$ with increasing solution molality and pressure and decreasing drop radii. Comparison of the calculated values of $T_{\mathrm{f}, \text { hom }}$ and $T_{\mathrm{m}}$ with existing experimental data on freezing ${ }^{1-6,45-48,51-53,55,56}$ and melting 15,21,22,52,55,56 shows in general good agreement. Calculated values of $T_{\mathrm{f} \text {,hom }}$ and $T_{\mathrm{m}}$, plotted as a function of water saturation ratio, exhibit mostly colligative properties, in agreement with experimental data. ${ }^{48,51,52,57,58,89}$ Some observed residual differences may be associated with the lower freezing temperatures of smaller drops in polydispersed ensembles.

Having calculated the melting and freezing point depressions, $\Delta T_{\mathrm{f}}$ and $\Delta T_{\mathrm{m}}$, we calculated the empirically derived parameter $\lambda=\Delta T_{\mathrm{f}} / \Delta T_{\mathrm{m}}$ and showed that the quasi-linear ratio $\lambda$ is not in conflict with classical nucleation theory as previously thought ${ }^{55}$ and that $\lambda$ is not strictly a constant but is a function of temperature, saturation ratio, and radius of freezing drops. However, the average values $\lambda=1.7-2$ used in applications ${ }^{21-27,32,33,39}$ can be a realistic approximation for drops of a few microns.

This method reasonably describes the pressure dependence of $T_{\mathrm{f}, \mathrm{hom}}$ and $T_{\mathrm{m}}$ including the change of slopes $\mathrm{d} T_{\mathrm{f}} / \mathrm{d} p$ when the type of nucleated ice varies and allows establishment of a quantitative equivalence between pressure and solution effects with a simple equation. However, this theory does not predict the change of the ice type because it does not consider the symmetry of the phases in its current state. The approach described here can be used not only for freezing and melting temperatures but also for estimation of the spinodal temperatures including negative pressures, ${ }^{5,80,84,90-94}$ where the pressure 
dependence of $r_{\mathrm{cr}}$ and $\Delta F_{\mathrm{cr}}$ is often neglected. The evaluation of glassy transitions with this method and more precise evaluation of spinodal lines might be possible using an equation of state that predicts water density ${ }^{75,81}$ or considering Landau's parameter of order ${ }^{95}$ for the phase symmetry. ${ }^{93,94}$

Classical nucleation theory depends critically on the thermodynamic parameters latent heat, interfacial surface tensions, activation energy, and densities of water and ice; incorrect choice of these parameters may result in apparent failure of the entire theory. ${ }^{5,41}$ The impact of emulsions and other different experimental conditions on these quantities could explain at least some differences in the measured $T_{\mathrm{f}, \mathrm{hom}}(w) .{ }^{21,22,47-54}$ There are different and sometimes contradicting parametrizations of these quantities, because their determination at low temperatures is not a simple task. Hence, reliable measurements or reconstruction of these parameters for various substances, especially at low temperatures and high pressures, are needed to confirm and advance our understanding of freezing and melting.

Note finally that the nonclassical nucleation theories (e.g., kinetic or cluster approaches and density functional theory $21,73,84,96,97)$ are free of some limitations of the classical theory (e.g., from the concept of surface tension) and hold promise for the future. However, the nonclassical theories are used mostly for studies of fundamental features of phase transitions and have not yet been incorporated into atmospheric models, where classical theory still remains the main tool in calculations of the nucleation rates as reviewed in the Introduction. The extensions of the theory presented in this paper allow their simple direct inclusion into the cloud and other geophysical models for evaluation of the nucleation rates of freezing and melting for various temperatures, solution compositions, and pressures, especially for the cases with simultaneous variation of these parameters.

\section{Nomenclature}

$A_{\mathrm{K}}$, coefficient in Kohler equation.

$A_{\rho}=1-\rho_{\mathrm{i}} / \rho_{\mathrm{w}}$, density function.

$a_{\mathrm{w}}, a_{\mathrm{i}}$, the activities of water and ice.

$C_{\mathrm{h}}, C_{\text {hom }}, C_{\text {het }}$, preexponential factors.

$C_{\epsilon}$, constant of the misfit strain energy.

$\Delta F_{\text {act }}$, activation energy.

$\Delta F_{\mathrm{cr}}$, critical germ energy.

$f\left(m_{\mathrm{is}}, x\right)$, geometrical factor of heterogeneous freezing.

$G=R T /\left(M_{\mathrm{w}} L_{\mathrm{m}}^{\mathrm{ef}}\right)$, dimensionless parameter.

$H_{\mathrm{v}, \mathrm{fr}}, H_{\mathrm{s}, \mathrm{fr}}, H_{\mathrm{m}}$, functions defined by eqs $2.7,2.15$, and 2.20 .

$h$, molar enthalpy.

$J_{\mathrm{h}}$, general notation for nucleation rate.

$J_{\text {hom }}, J_{\text {het }}$, homogeneous and heterogeneous nucleation rates.

$k$, Boltzmann constant.

$L_{\mathrm{m}}$, specific latent heat of melting.

$L_{\mathrm{m}}^{\mathrm{ef}}$, effective melting heat defined after eq 2.5 .

$\hat{M}$, molality.

$M_{\mathrm{w}}, M_{\mathrm{s}}$, molecular weights of water and solute.

$m_{\text {is }}=\cos \theta_{\text {is }}$, wettability parameter.

$m_{\mathrm{s}}, m_{\mathrm{w}}$, masses of solute and water in solution.

$N_{0}, N_{\mathrm{f}}, N_{\mathrm{u}}$, concentration of drops before freezing, and of frozen and unfrozen drops.

$p, p_{0}$, pressure and initial pressure.

$p_{\mathrm{w}}, p_{\mathrm{i}}$, pressures inside drop and crystal.

$\Delta p=p-p_{0}$.

$r_{\mathrm{cr}}, r_{\mathrm{d}}$, radii of ice/liquid germs and of crystal/drop.

$r_{\mathrm{N}}$, radius of insoluble particle.

$R$, universal gas constant.

$S_{\mathrm{w}}$. water saturation ratio.
$T, T_{0}$, temperature and triple point temperature.

$T_{f}, T_{\mathrm{f}, \text { hom }}, T_{\mathrm{f} \text {,het }}$, homogeneous and heterogeneous freezing temperatures.

$T_{\mathrm{m}}$, melting temperature.

$\Delta T_{\mathrm{f}}, \Delta T_{\mathrm{m}}$, freezing and melting point depressions.

$V_{\mathrm{d}}$, drop volume.

$v_{\mathrm{w}}, v_{\mathrm{i}}$, specific volumes of water and ice.

$w$, weight concentration of solute.

$\delta_{\mathrm{w}}=S_{\mathrm{w}}-1$, water supersaturation.

$\epsilon$, elastic misfit strain.

$\lambda$, an empirical coefficient in $\Delta T_{\mathrm{f}} / \Delta T_{\mathrm{m}}$ relation.

$\mu_{k}$, molar chemical potential of $k$ th substance.

$\mu_{k 0}$, chemical potential of pure kth substance.

$\theta_{\text {is, }}$, contact angle at the ice-substrate interface or at the solution-ice interface.

$\rho_{\mathrm{w}}, \rho_{\mathrm{i}}$, densities of water and ice.

$\Delta \rho=\rho_{\mathrm{w}}-\rho_{\mathrm{i}}$.

$\sigma_{\mathrm{is}}, \sigma_{\mathrm{sa}}, \sigma_{\mathrm{ia}}$, surface tensions at the ice-solution, solutionair, and ice-air interfaces.

$\tau_{\text {fr, }}$ characteristic "freezing time".

Acknowledgment. This research was supported by the NASA FIRE CRYSTAL Project and the US Department of Energy Atmospheric Radiation Measurement Program. We are grateful to Greg Dash, Paul DeMott, Neville Fletcher, Peter Hobbs, Hitoshi Kanno, Charles Knight, Thomas Koop, Ari Laaksonen, Osamu Mishima, Eugene Stanley, and John Wettlaufer for useful and stimulating discussions at various stages of this work. Hitoshi Kanno and Osamu Mishima are especially thanked for providing the digital data on freezing and melting temperatures. We are grateful to an anonymous reviewer for careful reading the manuscript and good remarks that allowed improvement the text. The invaluable help of Jody Norman in preparing the manuscript is gratefully acknowledged.

\section{References and Notes}

(1) Fletcher, N. H. The Physics of Rainclouds; Cambridge University Press: Cambridge, 1962.

(2) Dufour, L.; Defay, R. Thermodynamics of Clouds; Academic Press: New York, 1963.

(3) Defay, R.; Prigogine, I.; Bellemans, A. Surface Tension and Absorption; Wiley: New York, 1966.

(4) Young, K. Microphysical Processes in Clouds; Oxford University Press: Oxford, 1993.

(5) Pruppacher, H. R.; Klett, J. D. Microphysics of Clouds and Precipitation, 2nd ed.; Kluwer: Dordrecht, 1997.

(6) Hobbs, P. Ice Physics; Clarendon Press: Oxford, 1974.

(7) Marchuk, G. I.; Kondratyev; K. Y. Kozoderov; V. V.; Khvorostyanov, V. I. Clouds and Climate; Hydrometeorological Publishing House (Hydrometeoizdat): Leningrad, 1986.

(8) Seinfeld, J. H.; Pandis, S. N. Atmospheric Chemistry and Physics; Wiley: New York, 1997.

(9) Curry, J. A.; Webster, P. Thermodynamics of Atmospheres and Oceans; Academic Press: New York, 1999.

(10) Baker, M. B. Science 1997, 276, 1072.

(11) Worster, M. G.; Wettlaufer, J. S. J. Phys. Chem. B 1997, 101, 6132.

(12) Molina, L. T.; Molina, M. J. J. Phys. Chem. 1987, 91, 433.

(13) Solomon, S.; Garcia, R. R.; Rowland, F. S.; Wuebbles, D. J. Nature 1986, 321, 755 .

(14) Molina, M. J. Atmos. Environ. 1991, 25A, 2535.

(15) Dash, J. G.; Fu, H.; Wettlaufer, J. S. Rep. Prog. Phys. 1995, 58, 115.

(16) Rempel, A. W.; Wettlaufer, J. S.; Worster, M. G. J. Fluid Mech. 2004, 498, 227.

(17) Cuffey, K. M.; Conway, H.; Hallet, B.; Gades, A. M.; Raymond, C. F. Geophys. Res. Let. 1999, 26, 751.

(18) Baker, M. B.; Dash, J. G. J. Cryst. Growth 1989, 97, 770.

(19) Dash, J. G.; Mason, B. L.; Wettlaufer, J. S. J. Geophys. Res. 2001, 106,20395

(20) Liou, K. N. Mon. Weather Rev. 1986, 114, 1167.

(21) Martin, S. T. Chem. Rev. 2000, 100, 3403. 
(22) DeMott, P. J. In Cirrus; Lynch, D., Sassen, K., Starr, D. O’C., Stephens, G., Eds.; Oxford University Press: Oxford, 2002; pp 102-135.

(23) Sassen, K.; Dodd, G. C. J. Atmos. Sci. 1988, 45, 1357.

(24) Sassen, K.; Dodd, G. C. J. Atmos. Sci. 1989, 46, 3005.

(25) Sassen, K.; Benson, S. Geophys. Res. Lett. 2000, 27, 521

(26) Heymsfield, A. J.; Sabin, R. M. J. Atmos. Sci. 1989, 46, 22522264.

(27) DeMott, P. J.; Meyers, M. P.; Cotton, W. R. J. Atmos. Sci. 1994, $51,77$.

(28) Jensen, E. J.; Toon, O. B.; Westphal, D. L.; Kinne, S.; Heymsfield,

A. J. J. Geophys. Res. 1994, 99, 10,421.

(29) Jensen, E. J.; Toon, O. B.; Selkirk, H. B.; Spinhirne, J. D.; Schoeberl

M. R. J. Geophys. Res. 1996, 101, 21,361.

(30) Tabazadeh, A.; Jensen, E. J.; Toon, O. B. J. Geophys. Res. 1997, 102, D20, 23, 84 .

(31) Tabazadeh, A.; Toon, O. B. Geophys. Res. Lett. 1998, 25, 1379.

(32) DeMott, P. J.; Rogers, D. C.; Kreidenweis, S. M. J. Geophys. Res. 1997, 102, 19, 575.

(33) DeMott, P. J.; Rogers, D. C.; Kreidenweis, S. M.; Chen, Y.; Twohy, C. H.; Baumgardner, D.; Heymsfield, A. J.; Chan, K. R. Geophys. Res. Lett. 1998, 25, 1387.

(34) Khvorostyanov, V. I.; Sassen, K. Geophys. Res. Lett. 1998, 25(16), 3155 .

(35) Khvorostyanov, V. I.; Sassen, K. In Cirrus; Lynch, D., Sassen, K., Starr D. O’C., Stephens, G., Eds.; Oxford University Press: Oxford, 2002; pp 397-432.

(36) (a) Khvorostyanov, V. I.; Curry, J. A. Geophys. Res. Lett. 2000 27, 4081. (b) Khvorostyanov, V. I.; Curry J. A. J. Atmos. Sci. In press.

(37) Khvorostyanov, V. I.; Curry, J. A.; Pinto, J. O.; Shupe, M.; Lawson,

P.; Sassen, K. J. Geophys. Res. 2001, 106, 15099.

(38) Spice, A.; Johnson, D. W.; Brown, P. R. A.; Darlison, A. G.; Saunders, C. P. R. Q. J. R. Meteorol. Soc. 1999, 125, 1637.

(39) Lin, R.-F.; Starr, D. O'C.; DeMott, P. J.; Cotton, R.; Sassen, K.;

Jensen, E.; Kärcher, B.; Liu, X. J. Atmos. Sci. 2002, 60, 2305.

(40) Morrison, H.; Curry, J. A.; Khvorostyanov, V. I. J. Atmos. Sci. In press.

(41) Pruppacher, H. R. J. Atmos. Sci. 1995, 52, 1924.

(42) MacKenzie, A. R.; Laaksonen, A.; Batris, E.; Kulmala, M. J. Geophys. Res. D 1998, 103, 10875.

(43) Tabazadeh, A.; Martin, S. T.; Lin, J. S. Geophys. Res. Lett. 2000

$27,1111$.

(44) Kärcher, B.; Lohmann, U. J. Geophys. Res. 2002, 107, 4010, http:// dx.doi.org 10.1029/2001JD000470.

(45) Hagen, E. H.; Anderson, R. J.; Kassner J. L., Jr. J. Atmos. Sci. 1981, 32, 820.

(46) DeMott, P. J.; Rogers, D. C. J. Atmos. Sci. 1990, 47, 1056.

(47) Bertram, A. K.; Patterson, D. D.; Sloan, J. J. J. Phys. Chem. 1996 100,2376

(48) Koop, T.; H. Ng, P.; Molina, L. T.; Molina, M. J. J. Phys. Chem. A 1998, 102, 8924 .

(49) Cziczo, D. J.; Abbatt, J. P. D. J. Geophys. Res. 1999, 104, 13781.

(50) Prenni, A. J.; Wise, M. E.; Brooks, S. D.; Tolbert, M. A. J. Geophys. Res. 2001, 106, 3037

(51) Bertram, A. K.; Koop, T.; Molina, L. T.; Molina, M. J. J. Phys. Chem. A 2000, 104, 584

(52) (a) Koop, T.; Luo, B.; Tsias, A.; Peter, T. Nature 2000, 406, 611. (b) Koop, T. Bull. Chem. Soc. Jpn. 2002, 75, 2587.

(53) Chen, Y.; DeMott, P. J.; Kreidenweis, S. M.; Rogers, D. C.; Sherman, D. E. J. Atmos. Sci. 2000, 57, 3752.

(54) Chelf, J. H.; Martin, S. T. J. Geophys. Res. 2001, 106, 1215.

(55) Rasmussen, D. H. J. Cryst. Growth 1982, 56, 56.

(56) Rasmussen, D. H.; MacKenzie, A. P. In Water Structure and the Water Polymer Interface; Jellinek, H. H. G., Ed.; Plenum: New York, 1972; 126.
(57) Kanno, H.; Angell, C. A. J. Phys. Chem. 1977, 81, 2639

(58) Kanno, H.; Angell, C. A. J. Phys. Chem. 1979, 70, 4008

(59) Fletcher, N. H. Philos. Mag. 1968, 18, 1287.

(60) Ketcham, W. M.; Hobbs, P. V. Philos. Mag. 1969, 19, 1161.

(61) Knight, C. A. Philos. Mag. 1971, 23, 153.

(62) Elbaum, M., S.; Lipson, G.; Dash, J. D. J. Cryst. Growth 1993, $129,491$.

(63) Elbaum, M.; Schick, M. Phys. Rev. Lett. 1991, 66, 1713.

(64) Johari, J. P. Philos. Mag. 1998, 77, 1367.

(65) Wettlaufer, J. S. Phys. Rev. Lett. 1999, 82, 2516.

(66) Tabazadeh, A.; Djikaev, Y. S.; Hamill, P.; and Reiss, H. J. Phys. Chem. A 2002, 106, 10238.

(67) Djikaev, Y. S.; Tabazadeh, A.; Hamill, P.; Reiss, H. J. Phys. Chem. A 2002, 106, 10247.

(68) Thomson, J. J. Application of Dynamics to Physics and Chemistry,

1st ed.; Cambridge University Press: Cambridge, 1888.

(69) Thomson, W. (Lord Kelvin). Proc. R. Soc. 1870, 7, 63.

(70) Turnbull, D.; Vonnegut, B. Ind. Eng. Chem. 1952, 44, 1292.

(71) Johari, J. P. J. Chem. Phys. 1998, 109, 1070.

(72) (a) Khvorostyanov, V. I.; Curry, J. A.; Gultepe, I.; Strawbridge, K. J. Geophys. Res. 2003, 108, 4296. (b) Khvorostyanov, V. I.; Morrison,

H.; Curry, J. A.; Baumgardner, D.; Lawson, P. P. J. Geophys. Res. In press.

(73) Oxtoby, D. In Ice Physics and the Natural environment; Wettlaufer, J. S., Dash, J. G., Untersteiner, N., Eds.; NATO ASI Series I, SpringerVerlag: New York, 1999; Vol. 56, p 23.

(74) Johari, G. P.; Fleissner, G.; Hallbrucker, A.; Mayer, E. J. Phys. Chem. 1994, 98, 4719.

(75) Jeffery, C. A.; Austin, P. H. J. Geophys. Res. 1997, 102, 25269.

(76) Tang, I. N.; Munkelwitz, H. R. J. Geophys. Res. 1993, 99, 18801

(77) Chen, J. P. J. Atmos. Sci. 1994, 51, 3505.

(78) (a) Miyata, K.; Kanno, H.; Tomizawa, T.; Yoshimura, Y. Bull.

Chem. Soc. Jpn. 2001, 74, 1629. (b) Miyata, K.; Kanno, H.; Niino, T.

Tomizawa, K. Chem. Phys. Let. 2002, 354, 51.

(79) Millero, F. J. In Eighth Report of the Joint Panel on Oceanographic Tables and Standards; UNESCO Technological Papers in Marine Science; UNESCO: Paris 1978; No 28, Annex 6

(80) Kiselev, S. B.; Ely, J. F. J. Chem. Phys. 2002, 116, 5657.

(81) Poole, P. H.; Sciortino, F.; Grande, T.; Stanley, H. E.; Angell, C.

A. Phys. Rev. Lett. 1994, 73, 1632

(82) Tse, J. S. J. Chem. Phys. 1992, 96, 5482

(83) Tse, J. S.; et al. Nature 1999, 400, 647-649.

(84) Mishima, O.; Stanley, H. E. Nature 1998, 396, 329.

(85) Mishima, O. Nature 1996, 384, 546

(86) Johari, J. P. Philos. Mag. 1998, 78, 375.

(87) Wagner, W.; Saul, A.; Pruss, A. J. Phys. Chem. Ref. Data. 1994, 23,515 .

(88) Leberman, R.; Soper, A. K. Nature 1995, 378, 364

(89) Kanno, H.; Yokoyama, H.; Yoshimura, Y. J. Phys. Chem. B 2001, 105,2019

(90) Angell, C. A. In Water: A Comprehensive Treatise; Franks, F., Ed.; Plenum: New York, 1982; Vol. 7, pp 1-81.

(91) Speedy, R. J.; Angell, C. A. J. Chem. Phys. 1976, 65, 851

(92) Speedy, R. J. J. Phys. Chem. 1982, 86, 982

(93) Kiselev, S. B.; Ely, J. F. Physica A 2001, 299, 357

(94) Kiselev, S. B.; Ely, J. F. J. Chem. Phys. 2003, 118, 680.

(95) Landau, L. D.; Lifshitz, E. M. Statistical Physics; Pergamon

Press: New York, 1980, Part 1.

(96) Oxtoby, D. W. J. Phys.: Condens. Matter 1992, 4, 7627

(97) Laaksonen, A.; Talanquer, V.; Oxtoby, D. W. Annu. Rev. Phys. Chem. 1995, 46, 489. 